OPEN ACCESS

Edited by:

Milton Lima Neto,

São Paulo State University, Brazil

Reviewed by

Ana Karla M. Lobo,

São Paulo State University, Brazil

Aurenivia Bonifacio,

Federal University of Piauí, Brazi

Marcio Martins,

Universidade Federal do Acre, Brazil Gustaf E. Degen,

The University of Sheffield,

United Kingdom

*Correspondence.

Tingbo Dai

tingbod@njau.edu.cn

Zhongwei Tian

zhwtian@njau.edu.cn

Specialty section

This article was submitted to

Plant Physiology,

a section of the journal

Frontiers in Plant Science

Received: 03 March 2021

Accepted: 21 April 2021

Published: 11 June 2021

Citation:

Shao Y, Li S, Gao L, Sun C, Hu J, Ullah A, Gao J, Li X, Liu S, Jiang D,

Cao W, Tian Z and Dai T (2021)

Magnesium Application Promotes Rubisco Activation and Contributes

to High-Temperature Stress

Alleviation in Wheat During the Grain

Filling. Front. Plant Sci. 12:675582.

doi: $10.3389 / \mathrm{fp} / \mathrm{s} .2021 .675582$

\section{Magnesium Application Promotes Rubisco Activation and Contributes to High-Temperature Stress Alleviation in Wheat During the Grain Filling}

Yuhang Shao', Shiyu Li', Lijun Gao', Chuanjiao Sun', Jinling Hu', Attiq Ullah',

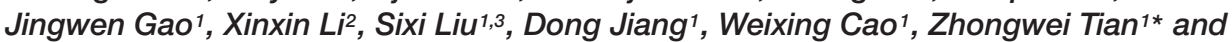
Tingbo Dai ${ }^{1 *}$

${ }^{1}$ Key Laboratory of Crop Physiology Ecology and Production Management, Ministry of Agriculture and Rural Affairs, Nanjing Agricultural University, Nanjing, China, ${ }^{2}$ Rural Energy and Environment Agency, Ministry of Agriculture and Rural Affairs, Beijing, China, ${ }^{3}$ Chengdu Agricultural Technology Extension Station, Chengdu, China

Inhibited photosynthesis caused by post-anthesis high-temperature stress (HTS) leads to decreased wheat grain yield. Magnesium (Mg) plays critical roles in photosynthesis; however, its function under HTS during wheat grain filling remains poorly understood. Therefore, in this study, we investigated the effects of $\mathrm{Mg}$ on the impact of HTS on photosynthesis during wheat grain filling by conducting pot experiments in controlled-climate chambers. Plants were subjected to a day/night temperature cycle of $32^{\circ} \mathrm{C} / 22^{\circ} \mathrm{C}$ for 5 days during post-anthesis; the control temperature was set at $26^{\circ} \mathrm{C} / 16^{\circ} \mathrm{C}$. Mg was applied at the booting stage, with untreated plants used as a control. HTS reduced the yield and net photosynthetic rate $\left(P_{n}\right)$ of wheat plants. The maximum carboxylation rate $\left(V_{C \max }\right)$, which is limited by Rubisco activity, decreased earlier than the light-saturated potential electron transport rate. This decrease in $\mathrm{V}_{C \max }$ was caused by decreased Rubisco activation state under HTS. Mg application reduced yield loss by stabilizing $P_{n}$. Rubisco activation was enhanced by increasing Rubisco activase activity following $\mathrm{Mg}$ application, thereby stabilizing $\mathrm{P}_{n}$. We conclude that $\mathrm{Mg}$ maintains Rubisco activation, thereby helping to stabilize $\mathrm{P}_{n}$ under HTS.

Keywords: wheat, high-temperature stress, magnesium, Rubisco activity, Rubisco activation, photosynthetic rate, high-temperature stress, photosynthetic rate

\section{INTRODUCTION}

Wheat is a C3 crop that grows during the winter and spring seasons, with an optimum grain filling temperature of $20-24^{\circ} \mathrm{C}$ (Paulsen, 1994; Shah and Paulsen, 2003; Li et al., 2012). The temperature threshold for grain filling in winter wheat is $25^{\circ} \mathrm{C}$ (Porter and Gawith, 1999; Wahid et al., 2007). When day/night temperatures increase to $30^{\circ} \mathrm{C} / 25^{\circ} \mathrm{C}$, the filling duration is shortened and dry matter accumulation decreases (Huebner and Bietz, 1988; Khan et al., 2020). However, the temperature often rises above $30^{\circ} \mathrm{C}$ in late spring, during the middle or late grain filling late stage, around the middle to lower reaches of the Yangtze River (World Weather Information Service). Grain yield can decrease by up to $30 \%$ at temperatures exceeding $32^{\circ} \mathrm{C}$ 
(Al-Khatib and Paulsen, 1990; Djanaguiraman et al., 2020). Global warming has increased the occurrence of intense hightemperature events (IPCC, 2020); as a result, high-temperature stress (HTS) on winter wheat during the grain filling stages restricts wheat production (Lesk et al., 2016).

Under favorable conditions, approximately $70-90 \%$ of the final grain yield is obtained from photosynthates produced during grain filling (Austin et al., 1977; Makunga et al., 1978; Chaudhuri et al., 2017). Longer leafing duration and higher photosynthetic activity contribute to yield increases in most major crops (Richards, 2000). However, high temperatures during post-anthesis restrict grain yield by reducing grain filling time and photosynthesis efficiency (Farooq et al., 2011). Photosynthesis is the basis of biomass production and is the physiological process that is most sensitive to elevated temperature, often showing inhibition before all other cellular functions at high temperatures (Berry and Bjorkman, 1980). Several photosynthetic pigment components of photosystem II (PSII), Rubisco carboxylation activity, stomatal opening, and other associated processes, are highly susceptible to HTS (Mathur et al., 2014). Damage to any of these components and processes is sufficient to interrupt the general photosynthetic mechanism (Ashraf and Harris, 2013; Mathur et al., 2014). However, the effects of HTS on the photosynthesis process during the wheat post-anthesis stage remain further understood.

Many studies have suggested that the loss of Rubisco activation is the main factor limiting the net photosynthesis rate under moderate HTS (Demirevska-Kepova and Feller, 2004; Salvucci and Crafts-Brandner, 2004b). Rubisco catalyzes the assimilation of $\mathrm{CO}_{2}$ during photosynthesis, and its catalytic limitations compromise photosynthesis efficiency (Parry et al., 2008; Lobo et al., 2019). Rubisco binds easily with inhibitors that block its active sites (Parry et al., 2008; Lobo et al., 2019). Rubisco activation state is defined as the fraction of active sites with catalytic activity and is regulated by Rubisco activase (RCA) (Boexfontvieille et al., 2014; Scafaro et al., 2016; Perdomo et al., 2017). Phosphate inhibitors can be removed from Rubisco active sites (carbamylated or not) via RCA activity in an ATP-dependent reaction (Streusand and Portis, 1987; Bracher et al., 2017). Under HTS, when Rubisco deactivation speeds up and photosynthesis is inhibited, the role of RCA becomes increasingly evident (Portis, 2003; Ristic et al., 2009; Scafaro et al., 2016; Perdomo et al., 2017). RCA is extremely sensitive to temperature (Kurek et al., 2007), but thermally stable RCA maintains high Rubisco activation levels and increases $\mathrm{CO}_{2}$ fixation efficiency (Kurek et al., 2007; Scafaro et al., 2016, 2019; Shivhare and MuellerCajar, 2017; Degen et al., 2020, 2021). Thus, improving RCA activity may be an effective method for maintaining a higher photosynthesis rate under HTS.

Magnesium $(\mathrm{Mg})$ is involved in several physiological and biochemical processes of plant growth and development (Waraich et al., 2011). Up to $15-35 \%$ of total $\mathrm{Mg}$ in plants is located in chloroplasts (Karley and White, 2009; Chen et al., 2018), where it is involved in photophosphorylation and $\mathrm{CO}_{2}$ fixation (Cakmak and YaziCi, 2010). Mg mainly plays roles in Rubisco activation and RCA catalysis (Parry et al., 2008). Mg deficiency adversely affects $\mathrm{CO}_{2}$ fixation, leading to reduced photosynthesis rates (Andersson, 2008), whereas adequate $\mathrm{Mg}$ has been shown to alleviate adverse effects of HTS in wheat and maize seedlings (Mengutay et al., 2013). Thus, Mg may play a significant part in carbon reactions, representing a possible mechanism for stabilizing the net photosynthesis rate under HTS.

High-temperature stress frequently occurs during the grain filling stage; however, few studies have examined $\mathrm{Mg}$ functions involved in photosynthesis under HTS during the grain filling stage. We hypothesized that under HTS, Mg application would enhance Rubisco activation, contributing to HTS alleviation. Therefore, we examined variation in Rubisco content and Rubisco activation state, light energy utilization efficiency under HTS to evaluate the effects of Mg application on Rubisco carboxylation activity, and electron transport capacity under HTS.

\section{MATERIALS AND METHODS}

\section{Plant Culture and Growth Conditions}

We conducted pot experiments at the Pailou Experimental Station of NAU, China $\left(32^{\circ} 04^{\prime} \mathrm{N}, 118^{\circ} 76^{\prime} \mathrm{E}\right)$, during the $2016-$ 2018 growing season. The local widely grown cultivar of Yangmai-16 (Triticum aestivum L.) was grown in plastic pots with a volume of $0.015 \mathrm{~m}^{3}$ (height, $30 \mathrm{~cm}$; diameter, $25 \mathrm{~cm}$ ), each with three holes at the bottom. Every pot was filled with $9 \mathrm{~kg}$ of air-dried and uniformly mixed clayey loam soil sieved through a $0.5-\mathrm{mm}$ mesh. The soil contained $11.78 \mathrm{~g} \mathrm{~kg}^{-1}$ organic matter, $0.87 \mathrm{~g} \mathrm{~kg}^{-1}$ total nitrogen (N), $81.37 \mathrm{mg} \mathrm{kg}^{-1}$ available potassium (K), $19.25 \mathrm{mg} \mathrm{kg}^{-1}$ available phosphate (P), and $110.9 \mathrm{mg} \mathrm{kg}^{-1}$ available $\mathrm{Mg}$. After soil filling, $5 \mathrm{~g}$ of compound fertilizer (15\% $\mathrm{N}, 15 \% \mathrm{P}$, and $15 \% \mathrm{~K}$ ) was applied to each treatment. At the jointing (Feekes 6.0) and booting stages (Feekes 10.0) (Miller, 1992), $0.45 \mathrm{~g}$ of $\mathrm{N}$ was applied to each pot. Each pot was sowed with 18 seeds, and then seedlings were scattered to eight in each pot at the three-leaf stage.

\section{Treatment Application and Management}

Magnesium fertilizer in the form of $\mathrm{MgSO}_{4} \cdot 7 \mathrm{H}_{2} \mathrm{O}$ was applied at $0.85 \mathrm{~g}$ per pot $\left(0.11 \mathrm{~g} \cdot \mathrm{kg}^{-1}\right)$ at the booting stage (Feekes 10.0 ), and pots without additional $\mathrm{Mg}$ application were used as controls (CK). The pots were moved to climate-controlled chambers set at a different temperature for 16-20 days after anthesis (DAA). HTS of the air temperature was simulated at $32^{\circ} \mathrm{C} / 22^{\circ} \mathrm{C}$, and $26^{\circ} \mathrm{C} / 16^{\circ} \mathrm{C}$ was applied as the optimal temperature (OT). The temperature setting during treatment days and the leaf temperature are shown in Supplementary Figure 1. Relative humidity in the chambers was at 65\%, under a light intensity of $1500 \mu \mathrm{mol}$ photons $\mathrm{m}^{-2} \mathrm{~s}^{-1}$ with a photoperiod of $16 \mathrm{~h}$. Each pot was watered about 2-4 1 each morning and evening during post-anthesis. Following treatment, pots were relocated in the OT growth chamber until maturity. Thus, the four treatments were CK-OT (control fertilizer with optimal temperature), CK-HT (control fertilizer with HTS), Mg-OT (additional $\mathrm{Mg}$ fertilizer with optimal temperature), and $\mathrm{Mg}-\mathrm{HT}$ (additional Mg fertilizer with HTS). 


\section{Plant Sampling and Measurements}

Plant sampling were conducted at 15DAA (prior to HTS treatment), 17DAA (2 days after treatment), 20DAA (5 days after treatment), and 25DAA. The flag leaves were detached from five randomly selected pots for each treatment and immediately submerged in liquid nitrogen for fresh sample measurements. Dry samples were collected from whole plants in five randomly selected pots of each treatment. We manually cut the plants at ground level using pruning scissors and then dried the samples at $105^{\circ} \mathrm{C}$ for $15 \mathrm{~min}$ in the oven, followed by $70^{\circ} \mathrm{C}$ until constant weight. The dried samples were ground for $\mathrm{N}$ and $\mathrm{Mg}$ content determination. Yield measurements at the maturity stage were tracked using the same five pots in each treatment.

\section{Gas Exchange and Fluorescence Measurements}

\section{Gas Exchange Measurements}

The gas exchange parameters were measured in flag leaves using the red and blue light source chamber (LI6400-02B) of a gas exchange machine (Li-Cor 6400, Li-Cor Inc., United States) in this study. The gas exchange parameter measurements were according to the methods by Gao et al. (2018) with modifications. Measurements were performed from 9:00 to 11:00 am under a light level of $1500 \mu \mathrm{mol}$ photons $\mathrm{m}^{-2} \mathrm{~s}^{-1}$. The vapor pressure deficit was between 0.5 and $1.0 \mathrm{kPa}$. The reference $\mathrm{CO}_{2}$ conference level was set at $400 \mu \mathrm{mol} \mathrm{mol}{ }^{-1}$, and the relative humidity of the leaf chamber was set to $55-65 \%$. The temperature of the leaf chamber was set according to real-time temperature in the growth chamber. The equipment was preheated for $0.5 \mathrm{~h}$ prior to measurement, and data were recorded three times after cuvette acclimatization for at least $5 \mathrm{~min}$.

The net photosynthesis rate/intercellular $\mathrm{CO}_{2}$ concentration $\left(\mathrm{A}-\mathrm{C}_{i}\right)$ curve was determined according to Gao et al. (2018). Measurements were conducted using the red and blue light source chamber of the Li-Cor 6400 photosynthesis instrument. The setting of light level and relative humidity was the same with the previous setting. $\mathrm{A} \mathrm{CO}_{2}$ injection system was used to control the $\mathrm{CO}_{2}$ concentration. Leaves were placed in the chamber for $10 \mathrm{~min}$ for adaptation. The $\mathrm{CO}_{2}$ concentration in the leaf chamber was then adjusted to values of $400,200,100$, $50,100,150,200,400,600,800,1000,1200$, and $1600 \mu \mathrm{mol}$ $\mathrm{mol}^{-1}$, and data were recorded for about 3 min per setting. Plotting $\mathrm{P}_{n}$ as the vertical coordinate and $\mathrm{C}_{i}$ as horizontal coordinate, the initial slope of the curve $\left(\mathrm{C}_{i}<200 \mu \mathrm{mol}\right.$ $\mathrm{mol}^{-1}$ ) represented carboxylation efficiency (CE). The Rubisco maximum carboxylation rate $\left(\mathrm{V}_{C \max }\right)$ and maximum electron transport rate $\left(\mathrm{J}_{\max }\right)$ were calculated according to modified equations (Long and Bernacchi, 2003; Li et al., 2009; Gao et al., 2018). The A-Ci curve is shown in the Supplementary Figure 2.

\section{Chlorophyll Fluorescence Measurements}

The fluorescence parameters were determined using the machine of CF Imager, Technologia Ltd, Colchester, United Kingdom. Following the methods of Gao et al. (2018), we selected leaves that had been adapted to the light for more than $30 \mathrm{~min}$ and recorded the steady-state fluorescence $\left(\mathrm{F}_{s}\right)$ and then applied a flash ( $~ 8000 \mu$ mol photons $\mathrm{m}^{-2} \mathrm{~s}^{-1}$ ) to record the maximum fluorescence under light $\left(\mathrm{F}_{m}{ }^{\prime}\right)$. We maintained the leaves in the dark for $3 \mathrm{~s}$, turned on the far-red light, then measured the initial fluorescence $\mathrm{F}_{o}$ ' under the light. Next, the leaves were shaded and dark-adapted for more than $30 \mathrm{~min}$, and the minimum $\left(\mathrm{F}_{o}\right)$ and maximum $\left(\mathrm{F}_{m}\right)$ chlorophyll fluorescence were recorded. Then, we calculated PSII efficiency $\left(\Phi_{P S I I}\right)$ as $\Phi_{P S I I}=\left(\mathrm{F}_{m}{ }^{\prime}-\mathrm{F}_{s}\right) / \mathrm{F}_{m}$, maximum fluorescence as $\mathrm{F}_{m}=\mathrm{F}_{m}-\mathrm{F}_{0} / \mathrm{F}_{m}$ (Genty et al., 1989), photoinhibitory quenching $(\mathrm{qL})$ as $\mathrm{qL}=\mathrm{F}_{0}{ }^{\prime} / \mathrm{F}_{s} \times\left(\mathrm{F}_{m}{ }^{\prime}-\mathrm{F}_{s}\right) /\left(\mathrm{F}_{m}{ }^{\prime}-\right.$ $\left.\mathrm{F}_{0}{ }^{\prime}\right)$ (Kramer et al., 2004), and the electron transport rate (ETR) as $\mathrm{ETR}=\left(\mathrm{F}_{m}{ }^{\prime}-\mathrm{F}_{s}\right) / \mathrm{F}_{m}{ }^{\prime} \times \mathrm{PPFD} \times 0.85 \times 0.5($ Li et al., 2009) .

\section{Physiological Measurements and Chemical Analysis \\ $\mathrm{N}$ and $\mathrm{Mg}$ Content Determination}

We used $100 \mathrm{mg}$ ground dried samples to determine $\mathrm{Mg}$ content. The samples were extracted using $5 \mathrm{~mL}$ of $\mathrm{HNO}_{3}$ and $\mathrm{HCl}$ solution $(1: 1 \mathrm{v} / \mathrm{v})$ for $4 \mathrm{~h}$ at $50^{\circ} \mathrm{C}$, and then the volume was adjusted to $20 \mathrm{~mL}$ using $\mathrm{ddH}_{2} \mathrm{O}$. Five biological repeats were conducted separately. Mg content was analyzed using the ICPOES, Optima 8000.

Total $\mathrm{N}$ analyses were conducted with the method from micro-Kjeldahl (Santos and Boiteux, 2013). Dried samples $(0.2 \mathrm{~g})$ from flag leaves were used. Five biological repeats were performed independently.

\section{Chlorophyll Content Measurements}

Chlorophyll concentrations were measured spectrophoto metrically according to Arnon (1949). We used $0.05 \mathrm{~g}$ of fresh flag leaves and $25 \mathrm{~mL}$ of a mixture of acetone and absolute ethanol (volume ratio 1:1) to extract leaf pigments. The samples were placed in a $30^{\circ} \mathrm{C}$ incubator for about $24 \mathrm{~h}$, and the extract was mixed several times. The absorbances at 470,645 , and $663 \mathrm{~nm}$ were measured to calculate the $\mathrm{Chl} \mathrm{a}$ and $\mathrm{Chl} \mathrm{b}$ concentrations, respectively. The chlorophyll concentration is the sum of Chl a and Chl b.

\section{Rubisco and Rubisco Activase (RCA) Content Determination}

Rubisco content was measured using SDS-PAGE following the methods of Makino et al. (1985) with modifications. We ground $10-\mathrm{cm}^{2}$ frozen leaf samples and extracted each sample in $5 \mathrm{~mL}$ of buffer solution prepared according to the methods. Then, we centrifuge the mixture at $15,000 \times \mathrm{g}$ for $15 \mathrm{~min}$ at $4^{\circ} \mathrm{C}$ and mixed the crude enzymatic extract with $5 \times$ loading buffer. We boiled $1 \mathrm{~mL}$ of the mixture for $1 \mathrm{~min}$ prior to electrophoresis. The amount of each sample was $10 \mu \mathrm{L}$ used in the electrophoresis which was at $100 \mathrm{~V}$ for about $8 \mathrm{~h}$. After that, the gels were stained with $0.25 \%(\mathrm{w} / \mathrm{v})$ Coomassie Blue R-250. The gels were destained with $25 \%$ ethanol and $8 \%$ glacial acetic acid solution. Subunits of 55 and $15 \mathrm{kDa}$ were put into a container with $2 \mathrm{~mL}$ of formamide. Then, the samples were kept in a $50^{\circ} \mathrm{C}$ water bath overnight. The absorbance at $595 \mathrm{~nm}\left(\mathrm{OD}_{595}\right)$ was measured. The calibration curve is shown in the Supplementary Figure 3.

Rubisco activase content was determined using an RCA Kit [Plant Rubisco Activase Enzyme-linked Immunoassay Assay (ELISA) Kit, Jianglai Biotechnology Co., Ltd., Shanghai] 
according to the manufacturer's instructions. The doubleantibody sandwich method was used to determine the RCA content of the plant according to Choi and Roh (2003) with modifications. Ten microliters of crude enzymatic extract with $40 \mu \mathrm{L}$ sample diluent was added with $100 \mu \mathrm{l}$ of rabbit antiRubisco activase antiserum in a 96-well microtiter plate, which were precoated with the RCA capture antibody. Then, the plate was incubated at $37^{\circ} \mathrm{C}$ for $60 \mathrm{~min}$. After washing the plate five times, $100 \mu \mathrm{L}$ peroxidase substrate was added. After mixing, the plate was kept in the dark for $15 \mathrm{~min}$ at room temperature. Finally, $1 \mathrm{M} \mathrm{HCl}$ was added to terminate the reaction. We measured $\mathrm{OD}_{450}$ within 15 min after adding the termination solution.

\section{Rubisco and RCA Activity Determination}

Rubisco activity was determined following the method of Sharwood et al. (2016). We measured the rate of NADH oxidation at $340 \mathrm{~nm}$. The NADH-linked assays retrieve lower values of Rubisco activity compared with the ${ }^{14} \mathrm{CO}_{2}$ fixation assay, but the NADH-linked assays were correlated strongly with the radiometric assay (Sales et al., 2020). NADH-linked assay is widely used in Rubisco activity, but microtiter plate-based assays may decrease the accuracy of the results (Sales et al., 2020), so we utilized cuvettes to measure the change in absorbance in a spectrophotometer. The recipes of extract buffer solution $[5 \mathrm{ml}$ $\mathrm{pH} 8.0$ buffer solution (50 mM pH 7.5 Tris- $\mathrm{HCl}$ ), $10 \mathrm{mM} \beta$ mercaptoethanol, $12.5 \%$ (v/v glycerol, $1 \mathrm{mM}$ EDTA-Na, $10 \mathrm{mM}$ $\mathrm{MgCl}_{2}, 1 \%(\mathrm{~m} / \mathrm{v})$ polyvinylpyrrolidone)], assay buffer solution (100 mmol EPPS-NaOH pH 8.0, 10 mmol $\mathrm{MgCl}_{2}, 1 \mathrm{mmol}$ EDTA, $0.2 \mathrm{mmol} \mathrm{NADH}, 20 \mathrm{mmol} \mathrm{NaHCO}_{3}, 5 \mathrm{mmol}$ dithiothreitol, $5 \mathrm{mmol}$ ATP, $10 \mathrm{U} \cdot \mathrm{ml}^{-1}$ creatine phosphokinase, $10 \mathrm{U} \cdot \mathrm{ml}^{-1}$ 3-phosphoglyceric phosphokinases, $10 \mathrm{U} \cdot \mathrm{ml}^{-1}$ glyceraldehyde3-phosphate dehydrogenases, and $5 \mathrm{mmol}$ phosphocreatine), and activating solution (50 mM Tris- $\mathrm{HCl} \mathrm{pH} \mathrm{7.5,} 40 \mathrm{mM} \mathrm{MgCl}$, $20 \mathrm{mM} \mathrm{NaHCO}_{3}$ ) were according to Gao et al. (2018). We ground $10-\mathrm{cm}^{2}$ frozen leaf samples and extracted each sample using $5 \mathrm{~mL}$ of $\mathrm{pH} 8.0$ buffer solution. The mixture was centrifuged at $15,000 \times g$ for $1 \mathrm{~min}$ at $4^{\circ} \mathrm{C}$. The initial Rubisco activity was measured using a cuvette containing $100 \mu \mathrm{L}$ of the crude enzymatic extract, $700 \mu \mathrm{L}$ of assay buffer, and $200 \mu \mathrm{L}$ of $10 \mathrm{mmol}$ RuBP. The change in absorbance at $340 \mathrm{~nm}$ was monitored for $60 \mathrm{~s}$ (3 s per measurement) at room temperature. To determine the total Rubisco activity, $100 \mu \mathrm{L}$ of crude enzymatic extract was activated for $10 \mathrm{~min}$ at $25^{\circ} \mathrm{C}$ in RuBP assay buffer by adding $100 \mu \mathrm{L}$ of activating solution. Next, $100 \mu \mathrm{L}$ of this mixture was added with $700 \mu \mathrm{L}$ of assay buffer and $200 \mu \mathrm{L}$ of $10 \mathrm{mmol}$ RuBP sequentially, and the OD value at $340 \mathrm{~nm}$ was monitored for $1 \mathrm{~min}$ ( $3 \mathrm{~s}$ per measurement). The ratio of the initial activity over the total activity was calculated as the Rubisco activation state.

Rubisco activase activity measurements were processed following the process from Carmo-Silva and Salvucci (2011). The uncarbamylated Rubisco in the desalt extracts promoted the formation of the inactive Rubisco-RuBP complex. Frozen leaves were rapidly extracted at $4^{\circ} \mathrm{C}$ with $5 \% \mathrm{PEG}_{3350}$ and $4 \mathrm{mM}$ RuBP and then incubated for $5 \mathrm{~min}$ at $4^{\circ} \mathrm{C}$. Next, the extract was added to two parallel ( $\mathrm{A}$ and $\mathrm{B}$ ) reactions at $25^{\circ} \mathrm{C}$. The recipes of the $\mathrm{A}$ and $\mathrm{B}$ solutions were according to
Carmo-Silva and Salvucci (2011). In these reactions, the RuBP concentration was $3.6 \mathrm{mM}$. Rubisco activation was tracked by evaluating Rubisco activity in aliquots taken at every half minute till $5 \mathrm{~min}$ after initiation of reaction. The rate of Rubisco activity was the increase in the fraction of Rubisco active sites from 1.5 to $3 \mathrm{~min}$ by determining the Rubisco activity in reactions without ATP.

\section{ATP and ADP Content Determination}

We used ATP and ADP Bioluminescence Assay Kit (Beyotime, Jiangsu, China) to determine ATP and ADP contents, respectively, following the manufacturer's instructions. Twenty milligrams of wheat leaf samples were collected in $200 \mu \mathrm{L}$ pre-chilled lysis buffer, and a glass homogenizer was used to fully lyse the leaf tissue. The samples were centrifuged at $10,000 \times g$ for $2 \mathrm{~min}$ at $4^{\circ} \mathrm{C}$. The supernatant was collected. The ATP detection working solution was prepared according to the kit protocol. To each well, we added $100 \mu \mathrm{L}$ of extract, followed by $100 \mu \mathrm{L}$ of working solution. The luciferase signals were detected for $30 \mathrm{~s}$ using a multifunctional microplate reader (SpectraMax M2). A standard ATP concentration curve ranging from $1 \mathrm{pM}$ to $1 \mathrm{M}$ was prepared by gradient dilution. ADP concentration measurements were conducted by conversion to ATP.

\section{Statistical Analysis}

All data were analyzed using the SPSS ver. 10.0 software (SPSS Inc., United States). Two-way analysis of variance was performed for all data, and the means were compared using Duncan's multiple-comparison tests at a significance level of $P<0.05$. We used a minimum of three biological replicates. All graphs presented were produced using the GraphPad Prism 9 (GraphPad Software, San Diego, CA, United States), and tables were produced using Microsoft Excel 2016 (Microsoft, Redmond, WA, United States).

\section{RESULTS AND DISCUSSION}

\section{Results}

\section{Grain Filling Duration, Biomass, and Yield}

High-temperature stress treatment significantly affected the 1000 -grain weight of wheat plants, resulting in decreased yield (Table 1). The 1000-grain weight was reduced by 8.37 and $8.48 \%$ in the CK-HT treatment and by 5.01 and $5.51 \%$ in the Mg-HT treatment, during 2016-2017 and 2017-2018, respectively. Grain yield was reduced by 10.28 and $10.89 \%$ in the CK-HT treatment and by 6.6 and $7.9 \%$ in the Mg-HT treatment during 2016-2017 and 2017-2018, respectively. Mg treatment reduced the loss in grain weight and yield caused by HTS.

After anthesis, CK-HT and Mg-HT treatment durations were shortened by about 3 days due to HTS (Table 1). However, the duration of $\mathrm{Mg}$-OT treatment was prolonged by about 3 days compared to CK-OT. As a result of HTS, biomass accumulation after anthesis declined more in CK-HT (12.91 and 16.12\%, 20162017 and 2017-2018, respectively) than in Mg-HT treatment (8.03 and 7.92\%) (Table 1). Biomass at maturity decreased under HTS treatment by 4.48 and $5.75 \%$ in CK-HT, and 2.94 and 


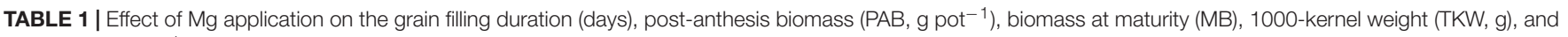
grain yield $\left(\mathrm{g} \mathrm{pot}^{-1}\right)$ of wheat under high-temperature stress (HTS) during grain filling.

\begin{tabular}{|c|c|c|c|c|c|c|}
\hline & Treatments & Filling duration & PAB & MB & TKW & Grain yield \\
\hline \multirow[t]{4}{*}{ 2016-2017 } & CK-OT & $34.67^{a b}$ & $33.71^{b}$ & $108.5^{b}$ & $41.20^{b}$ & $43.48^{b}$ \\
\hline & $\mathrm{CK}-\mathrm{HT}$ & $31.33^{\mathrm{C}}$ & $27.47^{\mathrm{c}}$ & $102.3^{\mathrm{C}}$ & $37.75^{\mathrm{C}}$ & $39.01^{c}$ \\
\hline & Mg-OT & $36.33^{a}$ & $36.11^{a}$ & $112.6^{a}$ & $44.43^{a}$ & $47.42^{a}$ \\
\hline & $\mathrm{Mg}-\mathrm{HT}$ & $34.00^{b}$ & $32.86^{b}$ & $109.3^{b}$ & $42.20^{b}$ & $44.29^{b}$ \\
\hline \multirow[t]{4}{*}{ 2017-2018 } & CK-OT & $35.33^{a b}$ & $33.50^{\mathrm{b}}$ & $111.1^{\mathrm{b}}$ & $43.04^{b}$ & $47.56^{b}$ \\
\hline & $\mathrm{CK}-\mathrm{HT}$ & $32.00^{\mathrm{C}}$ & $28.53^{c}$ & $106.1^{c}$ & $39.39^{c}$ & $42.38^{c}$ \\
\hline & Mg-OT & $37.33^{a}$ & $37.66^{a}$ & $116.5^{\mathrm{a}}$ & $46.28^{a}$ & $51.24^{\mathrm{a}}$ \\
\hline & $\mathrm{Mg}-\mathrm{HT}$ & $34.33^{b}$ & $34.24^{b}$ & $113.0^{\mathrm{b}}$ & $43.73^{b}$ & $47.17^{b}$ \\
\hline
\end{tabular}

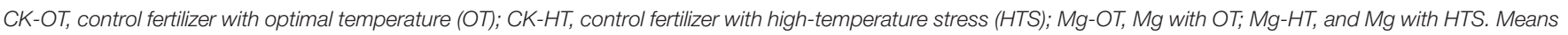

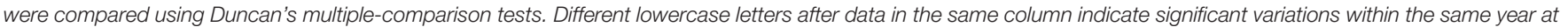
$P<0.05$.
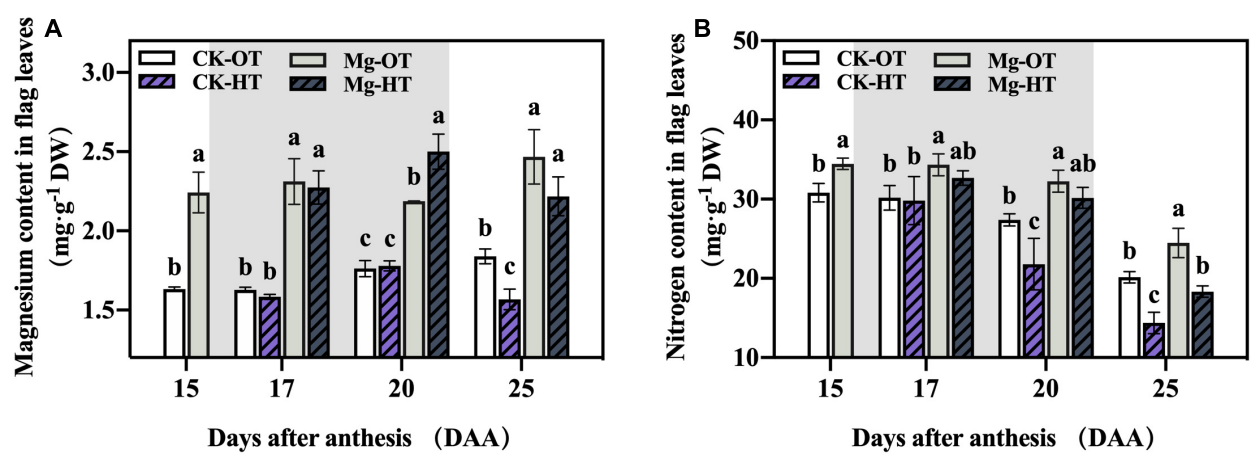

FIGURE 1 | Effect of Mg application on magnesium content $\left(\mathrm{mg} \cdot \mathrm{g}^{-1} \mathrm{DW}\right) \mathbf{( A )}$ and nitrogen content $\left(\mathrm{mg} \cdot \mathrm{g}^{-1} \mathrm{DW}\right)(\mathbf{B})$ under high-temperature stress during the grain filling. Treatments: CK-OT, control fertilizer + optimal temperature; CK-HT, control fertilizer + high temperature; Mg + OT, Mg fertilizer + optimal temperature;

$\mathrm{Mg}+\mathrm{HT}$, and Mg fertilizer + high temperature. The shaded area indicates the high -temperature treatment period. Two-way analysis of variance was performed, and the means were compared using Duncan's multiple-comparison tests. Different lowercase letters indicate significant variations within the same day at $P<0.05$; the error bars represent standard error (SE) of three biological replicates.

2.89\% in the Mg-HT treatment during both years (Table 1). These results indicate that $\mathrm{Mg}$ application enhanced biomass accumulation and reduced the loss induced by HTS.

\section{Mg and N Content}

The effects of $\mathrm{Mg}$ application on $\mathrm{Mg}$ and $\mathrm{N}$ content in flag leaves under HTS are shown in Figure 1. Mg application promoted increases in $\mathrm{Mg}$ and $\mathrm{N}$ content in flag leaves at 15DAA. Mg and $\mathrm{N}$ content did not change significantly in plants under HTS (CK-HT) relative to control plants (CK-OT) at 17DAA, but a reduction in $\mathrm{N}$ content was observed at 20DAA. At 25DAA, Mg and $\mathrm{N}$ contents in flag leaves of CK-HT decreased significantly. However, in Mg-treated plants, the $\mathrm{Mg}$ content of flag leaves increased dramatically at 20DAA and decreased at 25DAA in MgHT, although these differences were not significant compared to the Mg-OT treatment. The $\mathrm{N}$ content of flag leaves remained stable at 20DAA and decreased significantly at 25DAA in Mg-HT plants. These results indicate that $\mathrm{Mg}$ treatment increased the $\mathrm{Mg}$ and $\mathrm{N}$ content of flag leaves and reduced $\mathrm{N}$ loss induced by HTS.

\section{Photosynthesis and Related Attributes}

The $\mathrm{P}_{n}$ of wheat flag leaves under all treatments generally decreased during growth (Figure 2). HTS decreased $\mathrm{P}_{n}$
(9.93\%), transpiration rate $\left(\mathrm{T}_{r}\right)(5.64 \%)$, leaf stomatal conductance $\left(\mathrm{G}_{s}\right)(2.64 \%)$, and chlorophyll content $(3.33 \%)$ and increased $\mathrm{C}_{i}(8.84 \%)$ at 17DAA, although the changes in $\mathrm{G}_{s}, \mathrm{~T}_{r}$, and chlorophyll contents were not significant. At 20DAA, $\mathrm{P}_{n}, \mathrm{G}_{s}, \mathrm{~T}_{r}$, and chlorophyll contents decreased under HTS by 17.89, 9.14, 13.11, and 9.57\%, respectively, compared with CK-OT, whereas $\mathrm{C}_{i}$ increased significantly, by $11.10 \%$. Similar trends were observed at both 25DAA and 30DAA. At 17DAA in the Mg-HT treatment, $\mathrm{P}_{n}(4.30 \%)$, $\mathrm{G}_{s}(2.08 \%), \mathrm{T}_{r}(4.25 \%)$, and chlorophyll contents $(2.63 \%)$ were decreased and $\mathrm{Ci}(2.34 \%)$ was increased, but not significantly. At 20DAA, Mg-HT treatment stabilized $\mathrm{C}_{i}$ (4.91\% increase, less than CK-HT), and $\mathrm{P}_{n}, \mathrm{G}_{s}, \mathrm{~T}_{r}$, and chlorophyll contents decreased by $9.92,7.33,8.55$, and $6.10 \%$, respectively, compared to $\mathrm{Mg-OT}$. Plants were also less affected by HTS in the Mg-HT treatment than in the CK-HT treatment at 25DAA and 30DAA. The above results indicated that $\mathrm{Mg}$ could enhance the photosynthetic capability and stabilize that under HTS.

HTS decreased CE (27.27\%) and $\mathrm{V}_{C \max }(21.71 \%)$ at 17DAA in CK-HT and also decreased $\mathrm{J}_{\max }(5.02 \%)$, but not significantly (Table 2). CE, $\mathrm{V}_{C_{\max }}$, and $\mathrm{J}_{\max }$ decreased significantly at 20DAA and 25DAA. These findings indicate that $\mathrm{CE}$ and $\mathrm{V}_{\mathrm{Cmax}}$ were 

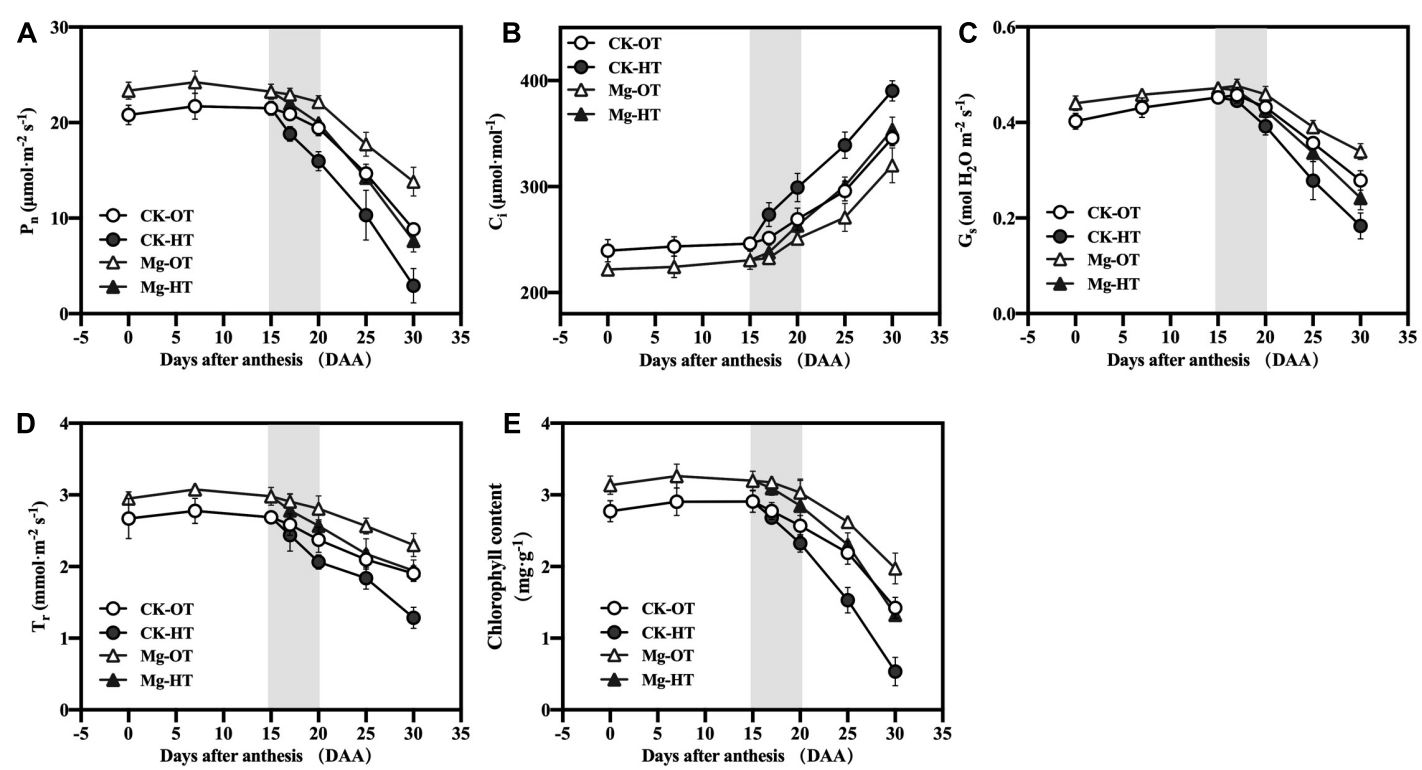

FIGURE 2 | Effect of $\mathrm{Mg}$ application on net photosynthesis rate $\left(\mathrm{P}_{n}\right)(\mathbf{A})$, intercellular $\mathrm{CO}_{2}$ concentration $\left(\mathrm{C}_{i}\right)$ (B), stomatal conductance $\left(\mathrm{G}_{s}\right)(\mathbf{C})$, transpiration rate $\left(T_{r}\right)(\mathbf{D})$, and chlorophyll content $(\mathbf{E})$ under high-temperature stress during the grain filling. Vertical bars above mean indicate the SE of five replicates at $P<0.5$.

TABLE 2 | Effects of Mg application on carboxylation efficiency (CE), light-saturated potential rate of electron transport $\left(J_{\max }, \mu \mathrm{mol} \cdot \mathrm{m}-2 \cdot \mathrm{s}-1\right)$, maximum carboxylation rate limited by Rubisco $\left(V_{C \max }, \mu \mathrm{mol} \cdot \mathrm{m}-2 \cdot \mathrm{s}-1\right)$ under HTS during the grain filling stage.

\begin{tabular}{|c|c|c|c|c|}
\hline & & $\mathrm{CE}$ & $\mathbf{v}_{C \max }$ & $\mathrm{J}_{\max }$ \\
\hline \multirow[t]{2}{*}{ 15DAA } & CK & $0.11^{\mathrm{b}}$ & $80.93^{b}$ & $170.07^{a}$ \\
\hline & $\mathrm{Mg}$ & $0.14^{a}$ & $91.35^{\mathrm{a}}$ & $175.90^{a}$ \\
\hline \multirow[t]{4}{*}{ 17DAA } & CK-OT & $0.11^{b}$ & $76.45^{b}$ & $164.87^{a t h}$ \\
\hline & CK-HT & $0.08^{\mathrm{C}}$ & $59.85^{c}$ & $156.60^{b}$ \\
\hline & Mg-OT & $0.13^{\mathrm{a}}$ & $89.82^{a}$ & $170.96^{a}$ \\
\hline & $\mathrm{Mg}-\mathrm{HT}$ & $0.13^{\mathrm{a}}$ & $82.74^{\mathrm{ab}}$ & $165.88^{\mathrm{at}}$ \\
\hline \multirow[t]{4}{*}{ 20DAA } & CK-OT & $0.10^{\mathrm{b}}$ & $67.24^{b}$ & $153.27^{a}$ \\
\hline & CK-HT & $0.07^{\mathrm{c}}$ & $51.03^{\mathrm{C}}$ & $129.81^{c}$ \\
\hline & Mg-OT & $0.13^{a}$ & $79.96^{a}$ & $159.73^{a}$ \\
\hline & $\mathrm{Mg}-\mathrm{HT}$ & $0.09^{b}$ & $69.82^{b}$ & $141.66^{b}$ \\
\hline \multirow[t]{4}{*}{ 25DAA } & CK-OT & $0.07^{b}$ & $55.10^{b}$ & $137.26^{a}$ \\
\hline & $\mathrm{CK}-\mathrm{HT}$ & $0.03^{c}$ & $38.87^{\mathrm{C}}$ & $87.03^{c}$ \\
\hline & Mg-OT & $0.10^{\mathrm{a}}$ & $68.89^{a}$ & $143.26^{a}$ \\
\hline & $\mathrm{Mg}-\mathrm{HT}$ & $0.06^{b}$ & $57.93^{b}$ & $105.57^{b}$ \\
\hline
\end{tabular}

Means were compared using Duncan's multiple-comparison tests. Different lowercase letters after data in the same column indicate significant variations within the same year at $P<0.05$.

inhibited earlier than $\mathrm{J}_{\max }$ under HTS. At 15DAA, Mg application improved $\mathrm{CE}$ and $\mathrm{V}_{\text {Cmax }}$. Moreover, compared with CK-HT, $\mathrm{V}_{\text {Cmax }}$ and $\mathrm{CE}$ did not change significantly following $\mathrm{Mg}$ treatment at 17DAA under HTS. At 20DAA and 25DAA, CE, $\mathrm{V}_{\text {Cmax }}$, and $\mathrm{J}_{\max }$ remained at higher levels in the $\mathrm{Mg}$ treatment than in CK. The difference responses between CK-HT and Mg$\mathrm{HT}$ at 17DAA suggested the $\mathrm{Mg}$ function in the photosynthesis process under HTS.

\section{Light Energy Utilization and ETR}

Light-dependent reactions showed that HTS did not decrease the maximum photochemical efficiency $\left(\mathrm{F}_{v} / \mathrm{F}_{m}\right)$ at 17DAA, but $\Phi_{P S I}$ and ETR decreased due to a reduction in $\mathrm{qL}$ in the CK-HT treatment (Table 3). Higher non-photochemical chlorophyll fluorescence quenching (NPQ) was observed in CK-HT at 17DAA. $\Phi_{P S I}, \mathrm{qL}, \mathrm{F}_{v} / \mathrm{F}_{m}$, and ETR decreased significantly at 20DAA and 25DAA, and NPQ increased. Mgtreated plants showed significantly higher $\Phi_{P S I}, \mathrm{qL}$, and ETR at 15DAA, which was consistent with $\mathrm{P}_{n}$ and its attributes. $\Phi_{P S I}, \mathrm{qL}, \mathrm{ETR}$, and $\mathrm{F}_{v} / \mathrm{F}_{m}$ were reduced at 20DAA and 25DAA in both CK-HT and $\mathrm{Mg}-\mathrm{HT}$, but smaller reductions were observed in Mg-HT plants. A small reduction in NPQ was also observed in Mg-treated plants under HTS. These results indicated that compared with the control, Mg-treated plants had a stronger light energy utilization ability and maintains electron transfer under HTS.

\section{Rubisco Content and Activation State}

Rubisco content and total activity decreased significantly under HTS at 20DAA and 25DAA (Figures 3A,B), but they did not change significantly at 17DAA. HTS led to significantly decreased initial activity at 17DAA, 20DAA, and 25DAA (Figures 3C,D). Mg-OT plants showed higher Rubisco content (Figure 3A), total and initial activity (Figures 3B,C), and activation state (Figure 3D) compared to CK-OT at 15DAA. Rubisco content, total activity, and initial activity were higher in Mg-OT plants than CK-OT at 17DAA, 20DAA, and 25DAA. Interestingly, the initial Rubisco activity and the activation state were maintained in $\mathrm{Mg}$-treated plants relative to CK-HT plants at 17DAA, although decreasing trends were observed in Mg-HT plants at 20DAA and 25DAA. 
TABLE 3 | Effects of Mg application on actual photochemical efficiency of PSII in the light $\left(\Phi_{P S I I}\right)$, photochemical quenching $(q \mathrm{~L})$, the maximum quantum efficiency of PSII $\left(F_{v} / F_{m}\right)$, electron transport rate (ETR), and non-photochemical quenching (NPQ) under HTS during the grain filling stage.

\begin{tabular}{lllllll}
\hline & Treatment & $\boldsymbol{\Phi}$ PSII & qL & ETR & NPQ & $\mathbf{F}_{\boldsymbol{v}} / \mathbf{F}_{\boldsymbol{m}}$ \\
\hline DAA15 & CK & $0.39^{\mathrm{b}}$ & $0.33^{\mathrm{b}}$ & $131.71^{\mathrm{b}}$ & $1.89^{\mathrm{a}}$ & $0.82^{\mathrm{ab}}$ \\
& Mg & $0.42^{\mathrm{a}}$ & $0.38^{\mathrm{a}}$ & $140.22^{\mathrm{a}}$ & $1.91^{\mathrm{a}}$ & $0.84^{\mathrm{a}}$ \\
DAA17 & CK-OT & $0.38^{\mathrm{b}}$ & $0.29^{\mathrm{b}}$ & $126.22^{\mathrm{b}}$ & $1.96^{\mathrm{b}}$ & $0.83^{\mathrm{a}}$ \\
& CK-HT & $0.32^{\mathrm{c}}$ & $0.24^{\mathrm{c}}$ & $107.52^{\mathrm{c}}$ & $2.37^{\mathrm{a}}$ & $0.82^{\mathrm{ab}}$ \\
& Mg-OT & $0.40^{\mathrm{a}}$ & $0.32^{\mathrm{a}}$ & $134.18^{\mathrm{a}}$ & $1.94^{\mathrm{b}}$ & $0.83^{\mathrm{a}}$ \\
DAA20 & Mg-HT & $0.39^{\mathrm{a}}$ & $0.31^{\mathrm{a}}$ & $131.41^{\mathrm{a}}$ & $2.05^{\mathrm{b}}$ & $0.83^{\mathrm{a}}$ \\
& CK-OT & $0.35^{\mathrm{b}}$ & $0.28^{\mathrm{b}}$ & $118.33^{\mathrm{b}}$ & $2.01^{\mathrm{c}}$ & $0.81^{\mathrm{a}}$ \\
& CK-HT & $0.30^{\mathrm{c}}$ & $0.22^{\mathrm{c}}$ & $100.62^{\mathrm{c}}$ & $2.74^{\mathrm{a}}$ & $0.76^{\mathrm{c}}$ \\
& Mg-OT & $0.38^{\mathrm{a}}$ & $0.32^{\mathrm{a}}$ & $128.10^{\mathrm{a}}$ & $2.03^{\mathrm{c}}$ & $0.83^{\mathrm{a}}$ \\
& MA-HT & $0.34^{\mathrm{b}}$ & $0.28^{\mathrm{b}}$ & $115.08^{\mathrm{b}}$ & $2.36^{\mathrm{b}}$ & $0.79^{\mathrm{b}}$ \\
& CK-OT & $0.24^{\mathrm{b}}$ & $0.26^{\mathrm{b}}$ & $79.18^{\mathrm{b}}$ & $2.35^{\mathrm{bc}}$ & $0.76^{\mathrm{b}}$ \\
& CK-HT & $0.16^{\mathrm{c}}$ & $0.15^{\mathrm{d}}$ & $54.99^{\mathrm{c}}$ & $3.48^{\mathrm{a}}$ & $0.73^{\mathrm{c}}$ \\
& Mg-OT & $0.30^{\mathrm{a}}$ & $0.30^{\mathrm{a}}$ & $102.14^{\mathrm{a}}$ & $2.03^{\mathrm{c}}$ & $0.78^{\mathrm{a}}$ \\
& Mg-HT & $0.26^{\mathrm{b}}$ & $0.21^{\mathrm{c}}$ & $87.14^{\mathrm{b}}$ & $2.73^{\mathrm{b}}$ & $0.75^{\mathrm{b}}$ \\
\hline
\end{tabular}

Means were compared using Duncan's multiple-comparison tests. Different lowercase letters after data in the same column indicate significant variations within the same day $(P<0.05, n=5)$.

Mg-HT plants showed a smaller decrease in initial Rubisco activity and activation state than CK-HT plants at 20DAA and 25DAA. This result was consistent with the result in Table 2.

\section{RCA Concentration and Activity}

The initial Rubisco activity and activation state depend on RCA activation. In our study, the total RCA pool was measured without distinguishing isoforms. The RCA concentration did not change significantly at 17DAA but decreased significantly in the CK-HT treatment at 20DAA and 25DAA (Figure 4A) and in the Mg-HT treatment at 25DAA. This result was consistent with our Rubisco content results. RCA activity in the Mg treatments was significantly higher than in $\mathrm{CK}$ at all stages (Figure 4B). Interestingly, HTS decreased RCA activity significantly at 17DAA in CK-HT but did not significantly affect that in the Mg-HT treatment. However, RCA activity decreased significantly under HTS in both CK and Mg treatments at 20DAA and 25DAA.

\section{ATP and ADP Content and ATP/ADP}

$\mathrm{Mg}$ application increased the ATP content and ATP/ADP ratio compared with CK in the OT treatment (Figure 5). However, there was no significant variation in ADP content between $\mathrm{CK}$ and Mg. HTS inhibited ATP synthesis, whereas Mg-HT sustained the ATP synthesis and high ATP/ADP ratios. The reduction in the content in ATP corresponded to the electron transfer rate. ATP and ADP content and the ATP/ADP ratio decreased under HTS at 20DAA and did not recover at 25DAA, indicating that the plants had reached senescence at 25DAA. Together, these results indicate that HTS inhibits ATP and ADP production and decreases the ratio of ATP over ADP but that $\mathrm{Mg}$ alleviates these losses.

\section{Correlations Among the Rubisco Activities, RCA Activity, and ATP/ADP Ratio}

The initial Rubisco activity and the total Rubisco activity were positively correlated with Rubisco activation state (Figure 6A), while the initial activity contributed more to increased Rubisco activation state than to total Rubisco activity. The RCA activity was also positively correlated with the activation state and the ATP/ADP ratio (Figures 6B,C). This implied that a higher $\mathrm{ATP} / \mathrm{ADP}$ ratio was closely related to the enhancement of the RCA activity, and then the activation state was also improved by higher Rubisco initial activity and RCA activity.

\section{Discussion Yield}

Global warming is a significant cause of HTS, which poses a serious threat to wheat production in many countries, especially during the reproductive and grain filling phases (Farooq et al., 2011; Khan et al., 2020). Wheat yield reduction under HTS is correlated with fewer spikes and smaller grains (Gibson and Paulsen, 1999; Lesk et al., 2016), whereas grain weight is significantly reduced by high temperatures in the middle and late stages of grain filling (Tahir and Nakata, 2005; Wajid et al., 2018). Assimilate transport from flag leaf to grain is substantially reduced by temperatures above $30^{\circ} \mathrm{C}$ (Plaut et al., 2004). In this study, HTS shortened the duration of the post-anthesis stage and decreased biomass accumulation (Table 1), seed weight, and grain yield. It has been proposed that grain weight was sensitive to the amount of the Mg in the soil (Potarzycki, 2008; Szulc, 2010; Grzebisz, 2013). In this study, the application of Mg fertilizer promoted crop growth and yield formation, which has also been alleviated under HTS. Leaf symptoms in Mg-deficient plants are similar to those of senescent leaves but can be recovered by sufficient Mg application (Uchida, 2000; Tanoi and Kobayashi, 2015). In this study, $\mathrm{Mg}$ application extended the duration of the grain filling stage and produced more biomass after anthesis under HTS, leading to higher grain weight and yield formation.

\section{$\mathrm{Mg}$ and $\mathrm{N}$ Content}

Under normal conditions, $\mathrm{Mg}$ content accounts for $0.15-0.35 \%$ of the dry weight of vegetative plant parts (Marschner, 1995; Tanoi and Kobayashi, 2015). During early vegetative growth, the critical whole-shoot $\mathrm{Mg}$ concentration is $0.1 \%$ for wheat (Jones and Wolf, 1991). In this study, Mg-treated plants alleviated yield loss under HTS and increased yield under normal temperature conditions, perhaps because $\mathrm{Mg}$ concentrations in the flag leaves of Mg-treated plants were at adequate levels (Mengutay et al., 2013), whereas CK plants were near the threshold of $\mathrm{Mg}$ deficiency. The most significant change during senescence is the breakdown of chloroplasts, which account for more than $70 \%$ of total N (Bascunan-Godoy et al., 2018). The rate of senescence and the remobilization of leaf $\mathrm{N}$ are related to the plant $\mathrm{N}$ nutrition status (Hortensteiner and Feller, 2002; Nehe et al., 2020). Previous studies have suggested that $\mathrm{Mg}$ application supports $\mathrm{N}$ uptake (Peng et al., 2019). Our findings also demonstrated that $\mathrm{Mg}$ promotes $\mathrm{N}$ accumulation, which were consistent with those of Peng et al. (2019). Additionally, HTS accelerates N degradation in flag leaves, whereas Mg stabilized $\mathrm{N}$ content, which suggests 

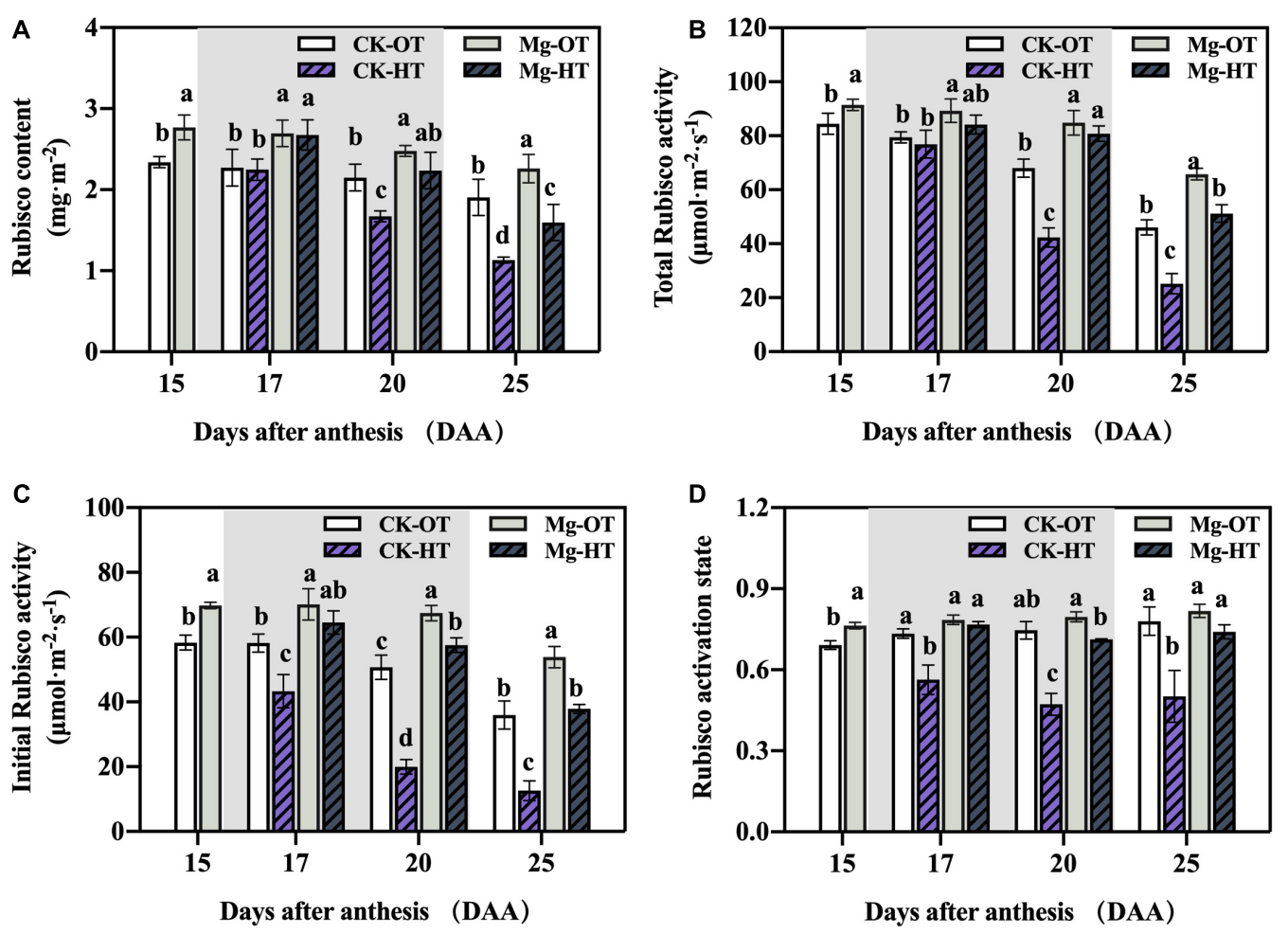

FIGURE 3 | Effect of Mg application on Rubisco content and activity under HTS during the grain filling stage. Two-way analysis of variance was performed; each bar is the mean \pm SE of five replications. Different lowercase letters indicate significant variations within the same day at $P<0.5$ (Duncan's multiple-comparison tests). (A) Rubisco content, (B) Total Rubisco activity, (C) Initial Rubisco activity, (D) Rubisco activation state.
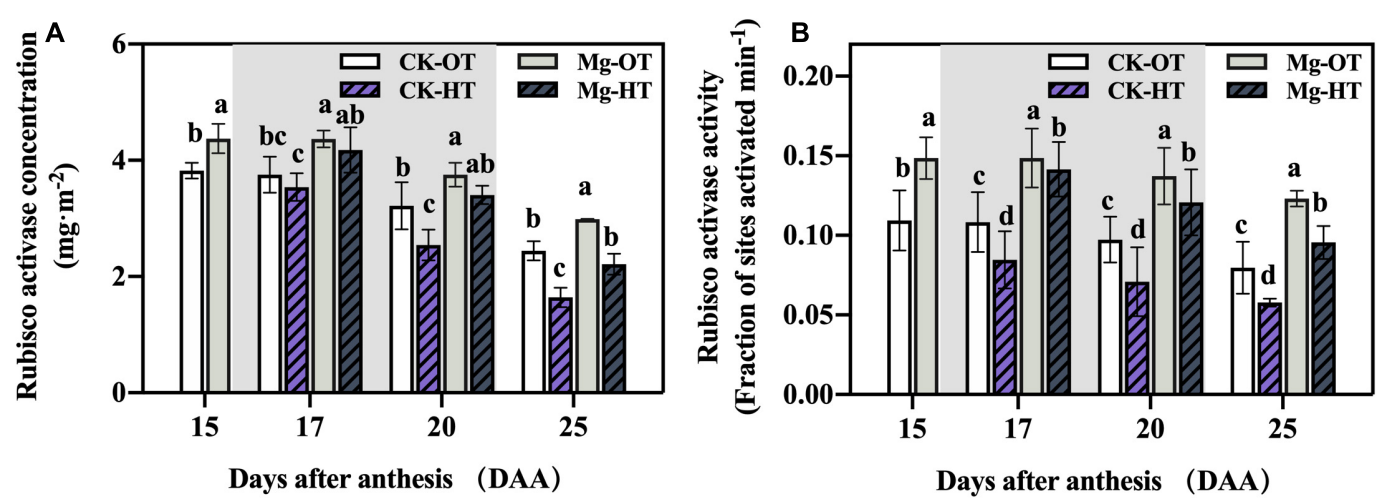

FIGURE 4 | Effect of Mg application on Rubisco activase concentration and activity under HTS during the grain filling stage. Two-way analysis of variance was performed; each bar is the mean \pm SE of five replications. Different lowercase letters indicate significant variations within the same day at $P<0.5$ (Duncan's multiple-comparison tests). (A) Rubisco activase concentration, (B) Rubisco activase activity.

that $\mathrm{Mg}$ alleviates senescence in flag leaves under HTS during the filling stage.

\section{Photosynthesis and Related Attributes}

Photosynthesis is pivotal to crop yield production, and photosynthetic capacity decreases gradually during plant senescence. Leaf photosynthesis is the physiological process that is most sensitive to HTS (Sabater and Martín, 2013), which significantly affects $\mathrm{P}_{n}, \mathrm{G}_{s}, \mathrm{~T}_{r}$, and $\mathrm{C}_{i}$ (Greer and Weedon, 2012;
Jahan et al., 2019). Reduced $\mathrm{P}_{n}$ under HTS appears to be caused by non-stomatal factors, because the stomata remain open and $C_{i}$ is not reduced when the photosynthetic structure is damaged (Mathur et al., 2014). In this study, $\mathrm{G}_{s}$ and $\mathrm{T}_{r}$ were not inhibited, but $\mathrm{P}_{n}$ decreased at 17DAA, indicating that the reduction in $\mathrm{P}_{n}$ under HTS in the early stages was not due to stomatal factors. Stabilization of leaf transpiration may be a way for wheat to improve leaf overheating (Yang et al., 2012). However, $C_{i}$ increased significantly, indicating that HTS reduced 

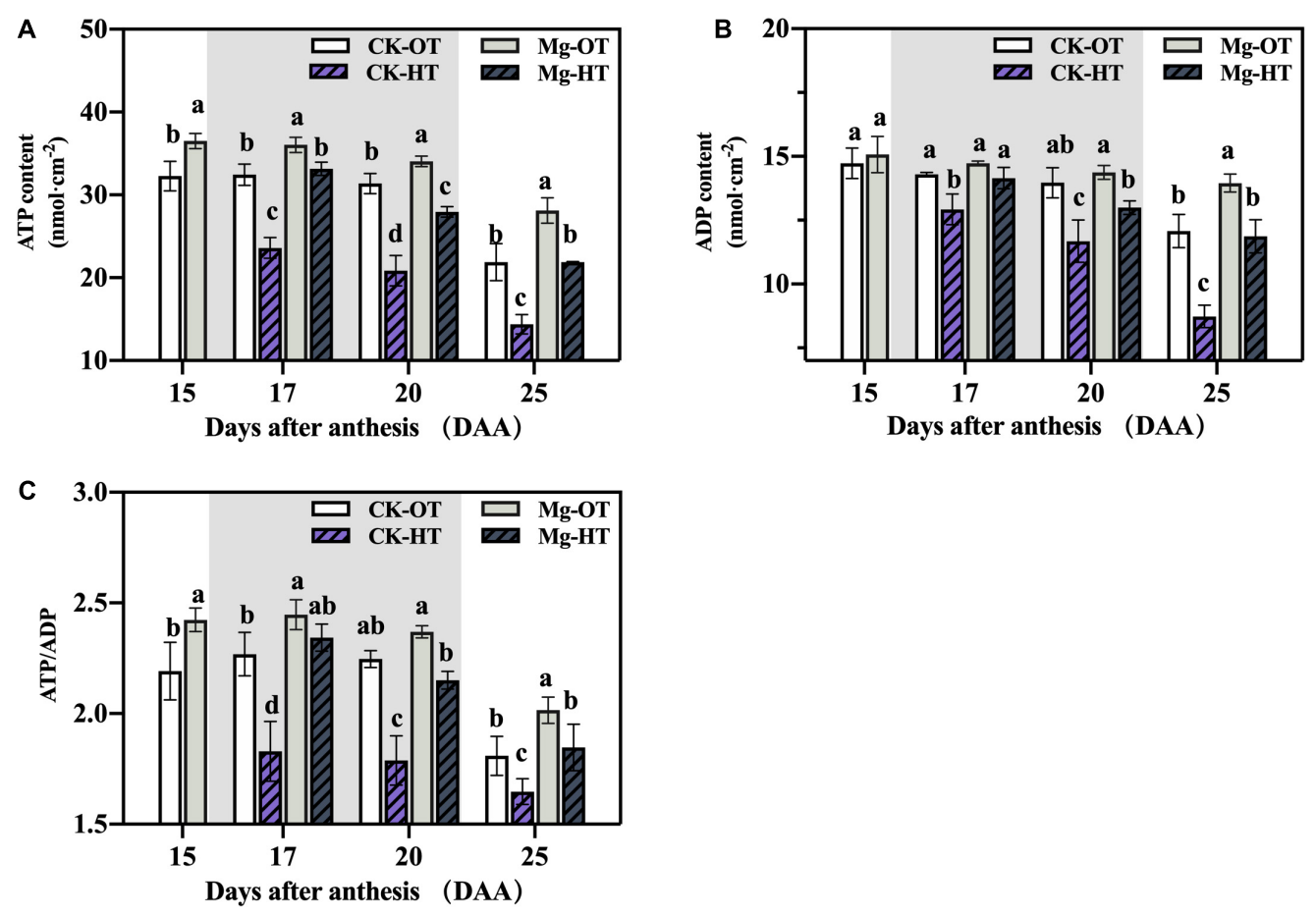

FIGURE 5 | Effects of Mg application on ATP content, ADP content, and ATP/ADP in flag leaves of wheat under HTS during grain filling. Two-way analysis of variance was performed; each bar is the mean \pm SE of five replications. Different lowercase letters indicate significant variations within the same day at $P<0.5$ (Duncan's multiple-comparison tests). (A) ATP content, (B) ADP content, (C) ATP/ADP.

$\mathrm{CO}_{2}$ utilization efficiency. $\mathrm{Mg}$ treatment improved $\mathrm{P}_{n}$ prior to HTS treatment. $\mathrm{P}_{n}$ has been found to be higher in Mg-sufficient plants than in Mg-deficient plants (Laing et al., 2000). In this study, $\mathrm{P}_{n}$ and $\mathrm{T}_{r}$ were stabilized in Mg-treated plants at 17DAA under HTS, compared with the CK. Similar Mg effects have been reported in Torreya grandis seedlings under toxic lead $\left(\mathrm{Pb}^{2+}\right)$ stress (Shen et al., 2016). Mg application also kept high levels of $\mathrm{G}_{s}$, which may be attributed to $\mathrm{Mg}$ playing a role in the regulation of anion-cation balance and cell turgor in cells along with K (Gerendás and Führs, 2013; Hasanah, 2018). In this study, photosynthetic capacity gradually decreased with wheat leaf senescence, and its inhibition by HTS was more significant at 25DAA and 30DAA, even in the $\mathrm{Mg}$ treatments, indicating that HTS irreversibly accelerates senescence during the grain filling stage in wheat.

The factors directly limiting photosynthesis at different degrees of HTS remain controversial because the photosynthetic system produces varying responses at different temperature ranges (Salvucci and Crafts-Brandner, 2004b; Yamori et al., 2013). $\mathrm{CE}, \mathrm{V}_{\text {Cmax }}$, and $\mathrm{J}_{\max }$ decreased under HTS (Weston and Bauerle, 2007; Ferguson et al., 2020). $V_{C \max }$ decreased earlier than $\mathrm{J}_{\max }$ at 17DAA, whereas both decreased synchronously at 20DAA and 25DAA; thus, $\mathrm{J}_{\max }$ decreased after $\mathrm{V}_{\text {Cmax }}$ inhibition. Under $\mathrm{Mg}$ application, $\mathrm{V}_{\text {Cmax }}$ did not decrease at 17DAA, indicating that $\mathrm{Mg}$ stabilized Rubisco carboxylation capacity under HTS. Even at 20DAA and 25DAA, these levels were higher under Mg treatment; thus, HTS may directly inhibit Rubisco carboxylation activity and electron transfer during the photosynthetic light reaction, whereas $\mathrm{Mg}$ stabilizes $\mathrm{V}_{\text {Cmax }}$ under short-term HTS, promoting carbon reactions.

\section{Light-Dependent Reaction}

The light system of plant leaves absorbs light energy and converts it into ATP and NADPH (Ashraf and Harris, 2013). When these processes are impaired, electron leakage damages the chloroplast structure (Wang et al., 2015). $\mathrm{F}_{v} / \mathrm{F}_{m}$ is a measure of photosynthetic capacity and can be used to verify the integrity of the PSII (Gregersen et al., 2014). In this study, under short-term HTS (17DAA), the $\mathrm{F}_{v} / \mathrm{F}_{m}$ of the light reaction system did not change, indicating that the photosynthetic light system of wheat leaves was not damaged under HTS, and the light reaction center retained its ability to self-regulate the photosynthetic system. This finding is consistent with our $\mathrm{J}_{\max }$ results. HTS also led to PSII closure in control plants by decreased $\mathrm{qL}$ and increased NPQ, which is a strategy for protecting the photosynthetic system under stress conditions (Maxwell and Johnson, 2000). However, PSII remained open in Mg-treated plants under HTS at 17DAA, and higher ETR and $\mathrm{F}_{v} / \mathrm{F}_{m}$ values were observed at 20DAA and 25DAA, indicating that $\mathrm{Mg}$ application under HTS in the grain filling stage promotes light energy utilization and electron transfer, which are beneficial to the synthesis of ATP and NADPH.

\section{Rubisco Activation}

Photosynthesis inhibition in wheat leaves under HTS is mainly caused by decreased Rubisco carboxylation activity 

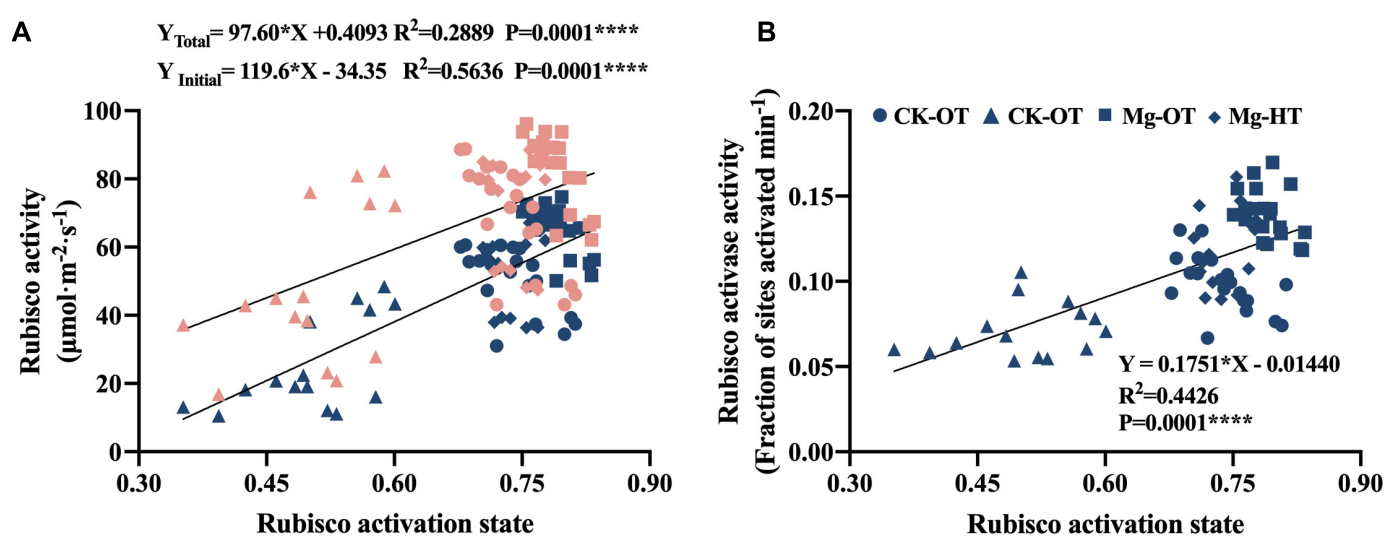

Total activity: $\odot$ CK-OT $\triangle$ CK-OT $\square$ Mg-OT $\diamond$ Mg-HT Initial activity: $\bullet$ CK-OT $\triangle$ CK-OT $\square$ Mg-OT $\bullet$ Mg-HT

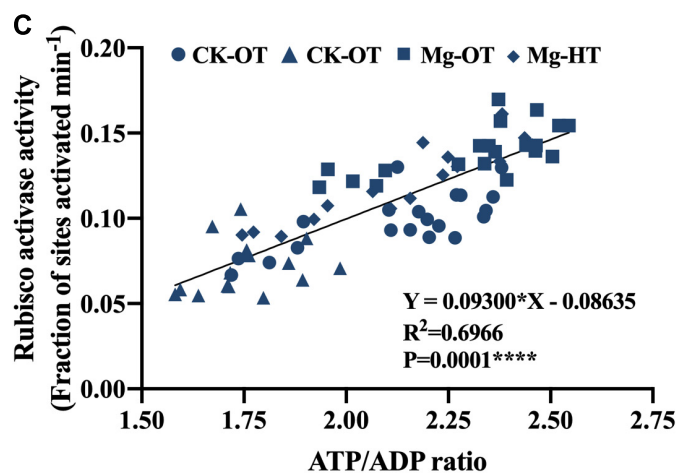

FIGURE 6 | Relationships between Rubisco activities, RCA activity, ATP/ADP ratio, and Rubisco activation state. Values of Rubisco activities, RCA activity, ATP/ADP

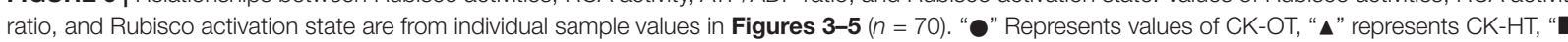
represents Mg-OT, and " $"$ " represents Mg-HT. The asterisks represent the statistical significance at the $P$ level shown in the figure, respectively. (A) ATP content. (B) ADP content. (C) ATP/ADP.

(Scaligero, 2004; Sharwood et al., 2016; Scafaro et al., 2019; Degen et al., 2020, 2021). However, Rubisco is actively degraded during leaf senescence (Imai et al., 2008). In this study, higher Rubisco content was found in Mg-treated plants, which may be related to the uptake of $\mathrm{N}$ by applying $\mathrm{Mg}$ (Peng et al., 2019), and the Rubisco content is positively correlated with leaf$\mathrm{N}$ content (Makino, 2003). Also, previous studies indicated that total Rubisco activity increased linearly with increasing leaf $\mathrm{N}$ (Cheng and Fuchigami, 2000). Therefore, the loss of the total Rubisco activity under HTS at 20DAA and 25DAA may be due to the reduction in the Rubisco amounts caused by accelerated senescence in the flag leaves. $\mathrm{Mg}$ stabilized the $\mathrm{N}$ content in the leaves, which alleviated the loss of Rubisco amount as well as the total Rubisco activity. However, in this study, under short-term HTS (17DAA), Rubisco content and total activity did not significantly decrease, whereas initial Rubisco activity and activation state were inhibited; this result suggests that Rubisco activation state and activity are sensitive to HTS. Various studies indicated that the decrease in the Rubisco activation state was the main cause of photosynthetic inhibition under moderate heat stress (Salvucci and Crafts-Brandner, 2004a; Degen et al., 2021) and a decrease in the activation state of Rubisco was thought to reflect a loss of carbamylation due to changes in stromal $\mathrm{pH}$ and $\mathrm{Mg}^{2+}$ concentration (Weis, 1981). In the present study, the initial Rubisco activity decreased earlier at 17DAA and decreased more at 20DAA compared with the total Rubisco activity, which is the reason for the reduction in the Rubisco activation state under HTS. Moreover, previous study has proposed that the decrease in $\mathrm{Mg}^{2+}$ level in chloroplast caused a significant reduction in Rubisco activity (Lasa et al., 2000). The Rubisco activation obviously depends on the $\mathrm{Mg}^{2+}$ concentration (Tcherkez, 2013). In the chloroplast, where $\mathrm{Mg}^{2+}$ total concentration is around 10-20 mM, the RuBP concentration at least twice as high as the concentration in Rubisco sites leads to an activation level of about 90\% (Von Caemmere, 1985; Tcherkez, 2013). In our results, Mg treatment significantly increased Rubisco activation state by increasing Rubisco activity, and the Rubisco activation state was stabilized under HTS at 20DAA and 25DAA. Further, in the analysis shown in Figure 6, a significant loss of the Rubisco amount caused reductions in the total Rubisco activity at 25DAA, and the initial Rubisco activity decreased significantly at that time. In contrast to previous observations (Perdomo et al., 2017; Degen et al., 2021), Rubisco activation state and Rubisco content were positively correlated, possibly due to the 
interplay between heat stress and the onset of leaf senescence. The Rubisco activation state and the total Rubisco activity were decreased synchronously after HTS during the late senescence stage. However, higher initial activity was more closely related to improvements in activation state.

Previous studies have shown that Rubisco enzymes bind easily with sugar phosphate or other substances, which inhibit its function (Parry et al., 2008, 2012; Scafaro et al., 2019; Degen et al., 2020, 2021). RCA and ATP can relieve Rubisco enzyme activity inhibition; therefore, RCA activity is important for stabilizing Rubisco activation (Parry et al., 2008). RCA is directly influenced by temperature (Carmo-Silva and Salvucci, 2012), and it showed the same trend between photosynthetic rate and RCA activity under HTS (Law and Craftsbrandner, 1999). The RCA activity is closely related to the heat tolerance level of wheat (Kumar et al., 2019). In the present study, HTS decreased RCA activity and concentration, but Mg treatment significantly increased RCA activity, which is consistent with the findings of previous studies (Liang et al., 2008; Kuriata et al., 2014; Hazra et al., 2015). Additionally, the RCA activity was also positively correlated with the Rubisco activation state (Figure 6B). Together, our results suggest that $\mathrm{Mg}$ promotes RCA activity, thereby stabilizing Rubisco activation under HTS during the wheat grain filling stage.

\section{Carboxylation and Light-Dependent Reactions Are Interrelated}

The $\mathrm{CO}_{2}$ assimilation reactions (Calvin-Benson cycle) consume ATP and NADPH to regenerate $\mathrm{NADP}^{+}$and ADP, reducing the light-dependent reaction and accepting transferred electrons during stable forward photosynthesis (Parry et al., 2008). Under HTS, ATP and ADP contents decreased, indicating the blockage of photoreaction ATP synthesis. Mg-treated plants had higher ATP content, which is consistent with the findings from Busch and Ninnemann (1997). We monitored RCA activity in terms of the ratio of ATP to ADP (Carmo-Silva et al., 2015). The positive correlation between the RCA activity and the ATP/ADP ratio implied that a higher $\mathrm{ATP} / \mathrm{ADP}$ ratio was closely related to the enhancement of the RCA activity (Figure 6C). HTS directly inhibited Rubisco activity, which influenced $\mathrm{NADP}^{+}$ and ADP reduction. Next, electron transfer was inhibited, which led to photoinhibition (Parry et al., 2008; Carmo-Silva and Salvucci, 2011; Mathur et al., 2014). Therefore, the photosynthetic system was damaged by an increase in redundant electrons. At 25DAA, ATP, and ADP contents remained higher in Mg-treated plants than in CK plants, and ATP/ADP increased significantly, indicating that Rubisco activation was maintained through $\mathrm{Mg}$ application, such that light energy utilization and electron transfer were relatively stabilized during the light reaction.

\section{REFERENCES}

Al-Khatib, K., and Paulsen, G. M. (1990). Photosynthesis and productivity during high-temperature stress of wheat genotypes from major world regions. Crop Sci. 30, 1127-1132. doi: 10.2135/cropsci1990.0011183X003000050034x

Andersson, I. (2008). Catalysis and regulation in Rubisco. J. Exp. Bot. 59, 15551568. doi: 10.1093/jxb/ern091

\section{CONCLUSION}

The results of the present study indicate that HTS caused a decrease in Rubisco carboxylation activity which inhibited photosynthesis during the wheat senescence stage, whereas $\mathrm{Mg}$ application maintained Rubisco carboxylation by enhancing its activation state and stabilizing the electron transfer rate. Thus, photosynthesis was sustained by $\mathrm{Mg}$ application under HTS. These results suggest that $\mathrm{Mg}$ plays an indispensable role in sustaining photosynthesis during grain filling by improving Rubisco activation state under HTS conditions.

\section{DATA AVAILABILITY STATEMENT}

The original contributions presented in the study are included in the article/Supplementary Material, further inquiries can be directed to the corresponding author/s.

\section{AUTHOR CONTRIBUTIONS}

YS, JH, CS, ZT, and TD conceived and designed the experiments. YS, JH, CS, SXL, and SYL developed methodologies. LG, SYL, JH, and JG analyzed the experimental data. SYL, LG, AU, YS, and XL wrote the manuscript. SXL, LG, AU, DJ, WC, ZT, and TD revised the manuscript. All the authors contributed to the article and approved the submitted version.

\section{FUNDING}

The National Key R\&D Program of China (2018YFD0300801) and the National Natural Science Foundation of China (Grant Nos. 31471443 and 31501262) supported the study.

\section{ACKNOWLEDGMENTS}

We acknowledge other researchers and staff for providing management and skills.

\section{SUPPLEMENTARY MATERIAL}

The Supplementary Material for this article can be found online at: https://www.frontiersin.org/articles/10.3389/fpls.2021. 675582/full\#supplementary-material

Arnon, D. I. (1949). Copper enzymes in isolated chloroplasts. Polyphenoloxidase in Beta vulgaris. Plant Physiol. 24, 1-15. doi: 10.1104/pp.24.1.1

Ashraf, M., and Harris, P. J. C. (2013). Photosynthesis under stressful environments: an overview. Photosynthetica 51, 163-190. doi: 10.1007/s11099013-0021-6

Austin, R. B., Edrich, J. A., Ford, M. A., and Blackwell, R. D. (1977). The fate of the dry matter, carbohydrates and $14 \mathrm{C}$ Lost from the leaves and stems of wheat 
during grain filling. Annal. Bot. 41, 1309-1321. doi: 10.1093/oxfordjournals. aob.a085419

Bascunan-Godoy, L., Sanhueza, C., Hernandez, C. E., Cifuentes, L., Pinto, K., Alvarez, R., et al. (2018). Nitrogen supply affects photosynthesis and photoprotective attributes during drought-induced senescence in quinoa. Front. Plant Sci. 9:994. doi: 10.3389/fpls.2018.00994

Berry, A. J., and Bjorkman, O. (1980). Photosynthetic response and adaptation to temperature in higher plants. Annu. Rev. Plant Physiol. 31, 491-543. doi: 10.1146/annurev.pp.31.060180.002423

Boexfontvieille, E., Daventure, M., Jossier, M., Hodges, M., Zivy, M., and Tcherkez, G. (2014). Phosphorylation pattern of Rubisco activase in Arabidopsis leaves. Plant Biol. 16:550. doi: 10.1111/plb.12100

Bracher, A., Whitney, S. M., Hartl, F. U., and Hayer-Hartl, M. (2017). Biogenesis and metabolic maintenance of rubisco. Annu. Rev. Plant Biol. 68, 29-60. doi 10.1146/annurev-arplant-043015-111633

Busch, K., and Ninnemann, H. (1997). The controlling influence of ADP, ATP and magnesium on the activities of adenylate kinase, ATP synthase, ADP/ATP translocator and the mitochondrial respiration in plants. Plant Sci. 128, 85-95. doi: 10.1016/s0168-9452(97)00117-9

Cakmak, I., and YaziCi, A. M. (2010). Magnesium: a forgotten element in crop production. Better Crops Plant Food 94, 23-25.

Carmo-Silva, A. E., and Salvucci, M. E. (2011). The activity of Rubisco's molecular chaperone, Rubisco activase, in leaf extracts. Photosynth. Res. 108, 143-155. doi: 10.1007/s11120-011-9667-8

Carmo-Silva, A. E., and Salvucci, M. E. (2012). The temperature response of $\mathrm{CO} 2$ assimilation, photochemical activities and Rubisco activation in Camelina sativa, a potential bioenergy crop with limited capacity for acclimation to heat stress. Planta 236, 1433-1445. doi: 10.1007/s00425-012-1691-1

Carmo-Silva, E., Scales, J. C., Madgwick, P. J., and Parry, M. A. (2015). Optimizing $\mathrm{R}$ ubisco and its regulation for greater resource use efficiency. Plant Cell Environ. 38, 1817-1832. doi: 10.1111/pce.12425

Chaudhuri, K. M., Dutta, P., and Das, S. (2017). Influence of homobrassinolide on photosynthetic traits during mid-grain filling stage and its impact on yield of wheat cultivars. J. Agricult. Phys. 17, 173-182.

Chen, Z. C., Peng, W. T., Li, J., and Liao, H. (2018). Functional dissection and transport mechanism of magnesium in plants. Semin. Cell Dev. Biol. 74, 142-152. doi: 10.1016/j.semcdb.2017.08.005

Cheng, L., and Fuchigami, L. H. (2000). Rubisco activation state decreases with increasing nitrogen content in apple leaves. J. Exp. Bot. 51, 1687-1694. doi: 10.1093/jexbot/51.351.1687

Choi, B. Y., and Roh, K. S. (2003). UV-B radiation affects chlorophyll and activation of rubisco by rubisco activase inCanavalia ensiformis L. leaves. J. Plant Biol. 46:117. doi: $10.1007 / \mathrm{bf} 03030440$

Degen, G. E., Orr, D. J., and Carmo-Silva, E. (2021). Heat-induced changes in the abundance of wheat Rubisco activase isoforms. New Phytol. 229, 1298-1311. doi: 10.1111/nph.16937

Degen, G. E., Worrall, D., and Carmo-Silva, E. (2020). An isoleucine residue acts as a thermal and regulatory switch in wheat Rubisco activase. Plant J. 103, 742-751. doi: 10.1111/tpj.14766

Demirevska-Kepova, K., and Feller, U. (2004). Heat sensitivity of Rubisco, Rubisco activase and Rubisco binding protein in higher plants. Acta Physiol. Plant. 26, 103-114. doi: 10.1007/s11738-004-0050-7

Djanaguiraman, M., Narayanan, S., Erdayani, E., and Prasad, P. V. V. (2020). Effects of high temperature stress during anthesis and grain filling periods on photosynthesis, lipids and grain yield in wheat. BMC Plant Biol. 20:268. doi: 10.1186/s12870-020-02479-0

Farooq, M., Bramley, H., Palta, J. A., and Siddique, K. H. M. (2011). Heat stress in wheat during reproductive and grain-filling phases. Cri. Rev. Plant Sci. 30, 491-507. doi: 10.1080/07352689.2011.615687

Ferguson, J. N., McAusland, L., Smith, K. E., Price, A. H., Wilson, Z. A., and Murchie, E. H. (2020). Rapid temperature responses of photosystem II efficiency forecast genotypic variation in rice vegetative heat tolerance. Plant J. 104, 839-855. doi: 10.1111/tpj.14956

Gao, J., Wang, F., Sun, J., Tian, Z., Hu, H., Jiang, S., et al. (2018). Enhanced Rubisco activation associated with maintenance of electron transport alleviates inhibition of photosynthesis under low nitrogen conditions in winter wheat seedlings. J. Exp. Bot. 69, 5477-5488.
Genty, B., Briantais, J.-M., and Baker, N. R. (1989). The relationship between the quantum yield of photosynthetic electron transport and quenching of chlorophyll fluorescence. Biochim. Biophys. Acta (BBA) Gen. Sub. 990, 87-92. doi: 10.1016/s0304-4165(89)80016-9

Gerendás, J., and Führs, H. (2013). The significance of magnesium for crop quality. Plant Soil 368, 101-128. doi: 10.1007/s11104-012-1555-2

Gibson, L., and Paulsen, G. (1999). Yield components of wheat grown under high temperature stress during reproductive growth. Crop Sci. 39, 1841-1846. doi: $10.2135 /$ cropsci1999.3961841x

Greer, D. H., and Weedon, M. M. (2012). Modelling photosynthetic responses to temperature of grapevine (Vitis vinifera cv. Semillon) leaves on vines grown in a hot climate. Plant Cell Environ. 35, 1050-1064. doi: 10.1111/j.1365-3040.2011. 02471.x

Gregersen, P. L., Foyer, C. H., and Krupinska, K. (2014). Photosynthesis and Leaf Senescence as Determinants of Plant Productivity: Biotechnological Approaches to Barley Improvement. Berlin: Springer, 113-138.

Grzebisz, W. (2013). Crop response to magnesium fertilization as affected by nitrogen supply. Plant Soil 368, 23-39. doi: 10.1007/s11104-012-1574-z

Hasanah, Y. S. M. (2018). Role of elicitors in chlorophyll content and stomatal density of soybean cultivars by foliar application. J. Agron. 17, 112-117. doi: 10.3923/ja.2018.112.117

Hazra, S., Henderson, J. N., Liles, K., Hilton, M. T., and Wachter, R. M. (2015). Regulation of ribulose-1,5-bisphosphate carboxylase/oxygenase (rubisco) activase: product inhibition, cooperativity, and magnesium activation. J. Biol. Chem. 290, 24222-24236. doi: 10.1074/jbc.M115.651745

Hortensteiner, S., and Feller, U. (2002). Nitrogen metabolism and remobilization during senescence. J. Exp. Bot. 53, 927-937. doi: 10.1093/jexbot/53. 370.927

Huebner, F. R., and Bietz, J. A. (1988). Quantitative variation among gliadins of wheats grown in different environments. Cereal Chem. 65, 362-366.

Imai, K., Suzuki, Y., Mae, T., and Makino, A. (2008). Changes in the synthesis of Rubisco in rice leaves in relation to senescence and N influx. Annal. Bot. 101, 135-144. doi: 10.1093/aob/mcm270

IPCC (2020). Special Report on Global Warming of $1.5^{\circ} \mathrm{C}$. Cambridge: Cambridge University Press.

Jahan, M. S., Wang, Y., Shu, S., Zhong, M., Chen, Z., Wu, J., et al. (2019). Exogenous salicylic acid increases the heat tolerance in Tomato (Solanum lycopersicum L) by enhancing photosynthesis efficiency and improving antioxidant defense system through scavenging of reactive oxygen species. Sci. Horticult. 247, 421-429. doi: 10.1016/j.scienta.2018.12.047

Jones, J. B., and Wolf, B. (1991). Plant Analysis Handbook: A Practical Sampling, Preparation, Analysis, and Interpretation Guide. Athens, GA: Micro-Macro Publishing, Inc.

Karley, A. J., and White, P. J. (2009). Moving cationic minerals to edible tissues: potassium, magnesium, calcium. Curr. Opin. Plant Biol. 12, 291-298. doi: 10. 1016/j.pbi.2009.04.013

Khan, M. A., Shirazi, M. U., Shereen, A., Ali, M., Asma, B. H., Jilani, N. S., et al. (2020). Agronomical and physiological perspectives for identification of wheat genotypes for high temperature tolerance. Pakist. J. Bot. 52, 1973-1980. doi: 10.30848/Pjb2020-6(12)

Kramer, D. M., Johnson, G., Kiirats, O., and Edwards, G. E. J. P. r. (2004). New fluorescence parameters for the determination of Q A redox state and excitation energy fluxes. Photosynth. Res. 79:209. doi: 10.1023/b:pres.0000015391.99477. Od

Kumar, R. R., Goswami, S., Dubey, K., Singh, K., Singh, J. P., Kumar, A., et al. (2019). RuBisCo activase-a catalytic chaperone involved in modulating the RuBisCo activity and heat stress-tolerance in wheat. J. Plant Biochem. Biotechnol. 28, 63-75. doi: 10.1007/s13562-018-0463-9

Kurek, I., Chang, T. K., Bertain, S. M., Madrigal, A., Liu, L., Lassner, M. W., et al. (2007). Enhanced thermostability of Arabidopsis Rubisco Activase improves photosynthesis and growth rates under moderate heat stress. Plant Cell 19, 3230-3241. doi: 10.1105/tpc.107.054171

Kuriata, A. M., Chakraborty, M., Henderson, J. N., Hazra, S., Serban, A. J., Pham, T. V., et al. (2014). ATP and magnesium promote cotton short-form ribulose-1, 5-bisphosphate carboxylase/oxygenase (Rubisco) activase hexamer formation at low micromolar concentrations. Biochemistry 53, 7232-7246. doi: 10.1021/ bi500968h 
Laing, W., Greer, D., Sun, O., Beets, P., Lowe, A., and Payn, T. (2000). Physiological impacts of $\mathrm{Mg}$ deficiency in Pinus radiata: growth and photosynthesis. New Phytol. 146, 47-57. doi: 10.1046/j.1469-8137.2000.00616.x

Lasa, B., Frechilla, S., Aleu, M., González-Moro, B., Lamsfus, C., and AparicioTejo, P. (2000). Effects of low and high levels of magnesium on the response of sunflower plants grown with ammonium and nitrate. Plant Soil 225, 167-174.

Law, R. D., and Craftsbrandner, S. J. (1999). Inhibition and acclimation of photosynthesis to heat stress is closely correlated with activation of ribulose1,5-bisphosphate carboxylase/oxygenase. Plant Physiol. 120, 173-181. doi: 10. 1104/pp.120.1.173

Lesk, C., Rowhani, P., and Ramankutty, N. (2016). Influence of extreme weather disasters on global crop production. Nature 529, 84-87. doi: 10.1038/ nature16467

Li, S., Wang, C., Chang, X., and Jing, R. (2012). Genetic dissection of developmental behavior of grain weight in wheat under diverse temperature and water regimes. Genetica 140, 393-405. doi: 10.1007/s10709-012-9688-Z

Li, Y., Gao, Y. X., Xu, X. M., Shen, Q. R., and Guo, S. W. (2009). Light-saturated photosynthetic rate in high-nitrogen rice (Oryza sativa L.) leaves is related to chloroplastic CO2 concentration. J. Exp. Bot. 60, 2351-2360. doi: 10.1093/jxb/ erp127

Liang, C., Xiao, W., Hao, H., Xiaoqing, L., Chao, L., Lei, Z., et al. (2008). Effect of $\mathrm{Mg} 2+$ on the structure and function of ribulose-1, 5-bisphosphate carboxylase/oxygenase. Biol. Trace Elem. Res. 121, 249-257.

Lobo, A. K. M., Orr, D. J., Gutierrez, M. O., Andralojc, P. J., Sparks, C., Parry, M. A. J., et al. (2019). Overexpression of calpase decreases rubisco abundance and grain yield in wheat. Plant Physiol. 181, 471-479. doi: 10.1104/pp.19.00693

Long, S. P., and Bernacchi, C. J. (2003). Gas exchange measurements, what can they tell us about the underlying limitations to photosynthesis? Procedures and sources of error. J. Exp. Bot. 54, 2393-2401. doi: 10.1093/jxb/erg262

Makino, A. (2003). Rubisco and nitrogen relationships in rice: leaf photosynthesis and plant growth. Soil Sci. Plant Nutr. 49, 319-327. doi: 10.1080/00380768. 2003.10410016

Makino, A., Mae, T., and Ohira, K. (1985). Enzymic properties of ribulose-1, 5bisphosphate carboxylase/oxygenase purified from rice leaves. Plant Physiol. 79, 57-61. doi: 10.1104/pp.79.1.57

Makunga, O., Pearman, I., Thomas, S., and Thorne, G. N. (1978). Distribution of photosynthate produced before and after anthesis in tall and semi-dwarf winter wheat, as affected by nitrogen fertiliser. Annal. Appl. Biol. 88, 429-437. doi: 10.1111/j.1744-7348.1978.tb00735.x

Marschner, H. (1995). Mineral Nutrition of Higher Plants, 2 Edn. London: Academic Press.

Mathur, S., Agrawal, D., and Jajoo, A. (2014). Photosynthesis: response to high temperature stress. J. Photochem. Photobiol. B Biol. 137, 116-126. doi: 10.1016/ j.jphotobiol.2014.01.010

Maxwell, K., and Johnson, G. N. (2000). Chlorophyll fluorescence-a practical guide. J. Exp. Bot. 51, 659-668. doi: 10.1093/jexbot/51.345.659

Mengutay, M., Ceylan, Y., Kutman, U. B., and Cakmak, I. (2013). Adequate magnesium nutrition mitigates adverse effects of heat stress on maize and wheat. Plant Soil 368, 57-72. doi: 10.1007/s11104-013-1761-6

Miller, T. D. (1992). Growth Stages of Wheat. Atlanta, GA: Potash \& Phosphate Institute, 76 .

Nehe, A., Misra, S., Murchie, E., Chinnathambi, K., Tyagi, B. S., and Foulkes, M. (2020). Nitrogen partitioning and remobilization in relation to leaf senescence, grain yield and protein concentration in Indian wheat cultivars. Field Crops Res. 251:107778. doi: 10.1016/j.fcr.2020.107778

Parry, M. A. J. K., Alfred, J., Madgwick, P. J., Carmo-Silva, A. E., and Andralojc, P. J. (2008). Rubisco regulation: a role for inhibitors. J. Exp. Bot. 59, 1569-1580. doi: 10.1093/jxb/ern084

Parry, M. A. J., Andralojc, P. J., Scales, J. C., Salvucci, M. E., Carmo-Silva, A. E., Alonso, H., et al. (2012). Rubisco activity and regulation as targets for crop improvement. J. Exp. Bot. 64, 717-730. doi: 10.1093/jxb/ers336

Paulsen, G. M. (1994). "High temperature responses of crop plants," in Physiology and Determination of Crop Yield, eds K. J. Boote, J. M. Bennett, T. R. Sinclair, and G. M. Paulsen (Madison, WI: ASA-CSSA-SSSA), 365-389. doi: 10.2134/ 1994.physiologyanddetermination.c25

Peng, W. T., Qi, W. L., Nie, M. M., Xiao, Y. B., Liao, H., and Chen, Z. C. (2019). Magnesium supports nitrogen uptake through regulating NRT2.1/2.2 in soybean. Plant Soil 457, 97-111. doi: 10.1007/s11104-019-04157-Z
Perdomo, J. A., Capó-Bauçà, S., Carmo-Silva, E., and Galmés, J. (2017). Rubisco and rubisco activase play an important role in the biochemical limitations of photosynthesis in rice, wheat, and maize under high temperature and water deficit. Front. Plant Sci. 8:490. doi: 10.3389/fpls.2017.00490

Plaut, Z., Butow, B. J., Blumenthal, C. S., and Wrigley, C. W. (2004). Transport of dry matter into developing wheat kernels and its contribution to grain yield under post-anthesis water deficit and elevated temperature. Field Crops Res. 86, 185-198. doi: 10.1016/j.fcr.2003.08.005

Porter, J. R., and Gawith, M. (1999). Temperatures and the growth and development of wheat: a review. Eur. J. Agron. 10, 23-36. doi: 10.1016/s11610301(98)00047-1

Portis, A. R. Jr. (2003). Rubisco activase - Rubisco's catalytic chaperone. Photosynth. Res. 75, 11-27. doi: 10.1023/a:1022458108678

Potarzycki, J. (2008). Influence of nitrogen and magnesium fertilization at the flag leaf stage of winter wheat development on the yield and grain quality. Nawozy $i$ Nawożenie 32, 100-110.

Richards, R. A. (2000). Selectable traits to increase crop photosynthesis and yield of grain crops. J. Exp. Bot. 51, 447-458. doi: 10.1093/jexbot/51.suppl_1.447

Ristic, Z., Momčilović, I., Bukovnik, U., Prasad, P. V., Fu, J., DeRidder, B. P., et al. (2009). Rubisco activase and wheat productivity under heat-stress conditions. J. Exp. Bot. 60, 4003-4014. doi: 10.1093/jxb/erp241

Sabater, B., and Martín, M. (2013). Chloroplast Control of Leaf Senescence. Dordrecht: Springer.

Sales, C. R. G., da Silva, A. B., and Carmo-Silva, E. (2020). Measuring Rubisco activity: challenges and opportunities of NADH-linked microtiter platebased and 14C-based assays. J. Exp. Bot. 71, 5302-5312. doi: 10.1093/jxb/er aa289

Salvucci, M. E., and Crafts-Brandner, S. J. (2004a). Inhibition of photosynthesis by heat stress: the activation state of Rubisco as a limiting factor in photosynthesis. Physiol. Plant. 120, 179-186. doi: 10.1111/j.0031-9317.2004. 0173.x

Salvucci, M. E., and Crafts-Brandner, S. J. (2004b). Relationship between the heat tolerance of photosynthesis and the thermal stability of Rubisco activase in plants from contrasting thermal environments. Plant Physiol. 134:1460. doi: $10.1104 /$ pp.103.038323

Santos, C. A., and Boiteux, L. S. (2013). Breeding biofortified cowpea lines for semi-arid tropical areas by combining higher seed protein and mineral levels. Embr. Hortal. Artigo Periód. Index. (ALICE) 12, 6782-6789. doi: 10.4238/2013. December.16.4

Scafaro, A. P., Bautsoens, N., den Boer, B., Van Rie, J., and Gallé, A. (2019). A conserved sequence from heat-adapted species improves Rubisco activase thermostability in wheat. Plant Physiol. 181, 43-54. doi: 10.1104/pp.19. 00425

Scafaro, A. P., Galle, A., Van Rie, J., Carmo-Silva, E., Salvucci, M. E., and Atwell, B. J. (2016). Heat tolerance in a wild Oryza species is attributed to maintenance of Rubisco activation by a thermally stable Rubisco activase ortholog. New Phytol. 211, 899-911. doi: 10.1111/nph. 13963

Scaligero, M. (2004). Inhibition of photosynthesis by heat stress: the activation state of Rubisco as a limiting factor in photosynthesis. Physiol. Plant. 120, 179-186. doi: 10.1111/j.0031-9317.2004.0173.x

Shah, N. H., and Paulsen, G. M. (2003). Interaction of drought and high temperature on photosynthesis and grain-filling of wheat. Plant Soil 257, 219-226. doi: 10.1023/a:1026237816578

Sharwood, R. E., Sonawane, B. V., Ghannoum, O., and Whitney, S. M. (2016). Improved analysis of C4 and C3 photosynthesis via refined in vitro assays of their carbon fixation biochemistry. J. Exp. Bot. 67, 31373148.

Shen, J., Song, L., Muller, K., Hu, Y., Song, Y., Yu, W., et al. (2016). Magnesium alleviates adverse effects of lead on growth, photosynthesis, and ultrastructural alterations of torreya grandis seedlings. Front. Plant Sci. 7:1819. doi: 10.3389/ fpls.2016.01819

Shivhare, D., and Mueller-Cajar, O. (2017). In vitro characterization of thermostable CAM Rubisco activase reveals a Rubisco interacting surface loop. Plant Physiol. 174, 1505-1516. doi: 10.1104/pp.17.00554

Streusand, V., and Portis, A. R. (1987). Rubisco activase mediates ATP-dependent activation of ribulose bisphosphate carboxylase. Plant Physiol. 85, 152-154. doi: $10.1104 /$ pp.85.1.152 
Szulc, P. (2010). Response of maize hybrid (Zea mays L.), stay-green type to fertilization with nitrogen, sulphur, and magnesium. Part I. Yields and chemical composition. Acta Scient. Polon. Agricult. 10, 29-40.

Tahir, I. S. A., and Nakata, N. (2005). Remobilization of nitrogen and carbohydrate from stems of bread wheat in response to heat stress during grain filling. J. Agron. Crop Sci. 191, 106-115. doi: 10.1111/j.1439-037x.2004.00127.x

Tanoi, K., and Kobayashi, N. I. (2015). Leaf senescence by magnesium deficiency. Plants 4, 756-772. doi: 10.3390/plants4040756

Tcherkez, G. (2013). Modelling the reaction mechanism of ribulose-1, 5bisphosphate carboxylase/oxygenase and consequences for kinetic parameters. Plant Cell Environ. 36, 1586-1596. doi: 10.1111/pce.12066

Uchida, R. (2000). Essential nutrients for plant growth: nutrient functions and deficiency symptoms. Plant Nutr. Manag. Hawaiis Soils 20, 31-55.

Von Caemmere, S. (1985). Kinetics and activation of Rubisco and some preliminary modelling of RuP_2 pool sizes. Kinet. Photosynth. Photorespir. C 3 Plants 85, 46-48.

Wahid, A., Gelani, S., Ashraf, M., and Foolad, M. R. (2007). Heat tolerance in plants: An overview. Environ. Exp. Bot. 61, 199-223. doi: 10.1016/j.envexpbot. 2007.05.011

Wajid, M., Khan, M. A., Shirazi, M. U., Summiya, F., and Saba, M. (2018). Seed priming induced high temperature tolerance in wheat by regulating germination metabolism and physio-biochemical properties. Int. J. Agricult. Biol. 20, 2140-2148.

Wang, J., Leister, D., and Bolle, C. (2015). Photosynthetic lesions can trigger accelerated senescence in Arabidopsis thaliana. J. Exp. Bot. 66, 6891-6903. doi: $10.1093 /$ jxb/erv393

Waraich, E. A., Ahmad, R., Saifullah, U., Ashraf, M. Y., and Ehsanullah. (2011). Role of mineral nutrition in alleviation of drought stress in plants. Austr. J. Crop Sci. 5, 764-777.
Weis, E. (1981). Reversible effects of high, sublethal temperatures on light-induced light scattering changes and electrochromic pigment absorption shift in spinach leaves. Zeitschr. Pflanzenphysiol. 101, 169-178. doi: 10.1016/s0044-328x(81) 80051-7

Weston, D. J., and Bauerle, W. L. J. T. P. (2007). Inhibition and acclimation of C3 photosynthesis to moderate heat: a perspective from thermally contrasting genotypes of Acer rubrum (red maple). Tree Physiol. 27, 1083-1092. doi: 10.1093/treephys/27.8. 1083

Yamori, W., Hikosaka, K., and Way, D. A. (2013). Temperature response of photosynthesis in $\mathrm{C} 3, \mathrm{C} 4$, and CAM plants: temperature acclimation and temperature adaptation. Photosynth. Res. 119, 101-117. doi: 10.1007/s11120013-9874-6

Yang, Z. J., Sinclair, T. R., Zhu, M., Messina, C. D., Cooper, M., and Hammer, G. L. (2012). Temperature effect on transpiration response of maize plants to vapour pressure deficit. Environ. Exp. Bot. 78, 157-162. doi: 10.1016/j.envexpbot.2011. 12.034

Conflict of Interest: The authors declare that the research was conducted in the absence of any commercial or financial relationships that could be construed as a potential conflict of interest.

Copyright (c) 2021 Shao, Li, Gao, Sun, Hu, Ullah, Gao, Li, Liu, Jiang, Cao, Tian and Dai. This is an open-access article distributed under the terms of the Creative Commons Attribution License (CC BY). The use, distribution or reproduction in other forums is permitted, provided the original author(s) and the copyright owner(s) are credited and that the original publication in this journal is cited, in accordance with accepted academic practice. No use, distribution or reproduction is permitted which does not comply with these terms. 